\title{
GUIA DAS BORBOLETAS FRUGÍVORAS DA RESERVA ESTADUAL DO MORRO GRANDE E REGIÃO DE CAUCAIA DO ALTO, COTIA (SÃO PAULO)
}

Marcio Uehara-Prado ${ }^{1,2}$, André Victor Lucci Freitas ${ }^{1}$, Ronaldo Bastos Francini ${ }^{3}$, Keith Spalding Brown Jr. ${ }^{1}$

Biota Neotropica v4 (n1) - http://www.biotaneotropica.org.br/v4n1/pt/abstract?inventory+BN00504012004

\author{
Recebido em: 14/08/2003 \\ Revisado em: 26/01/2004 \\ Publicado em: 12/02/2004
}

\footnotetext{
${ }^{1}$ Museu de História Natural e Departamento de Zoologia, Instituto de Biologia, Universidade Estadual de Campinas, CP 6109 CEP 13084-971 Campinas, SP

${ }^{2}$ Curso de Pós-Graduação em Ecologia, Instituto de Biologia, Universidade Estadual de Campinas, C.P.6109 CEP 13084971 Campinas, SP

${ }^{3}$ Universidade Católica de Santos, Campus D. Idílio José Soares, Av. Cons. Nébias n³00, Prédio dos Laboratórios, Sala 213, CEP 11015-200, Santos, SP
}

\begin{abstract}
The frugivorous butterflies species (Lepidoptera: Nymphalidae) known from Morro Grande Forest Reserve and Caucaia do Alto (Cotia, SP) are presented as a field guide.
\end{abstract}

Key words: Frugivorous Butterflies, Field Guide, Conservation, Inventory.

\section{Resumo}

As espécies de borboletas frugívoras (Lepidoptera: Nymphalidae) conhecidas da Reserva Estadual do Morro Grande (Cotia, SP) e Caucaia do Alto são apresentadas na forma de um guia de campo.

Palavras-chave:Taxonomia, Frugivorous Butterflies, Field Guide, Conservation, Inventory.

http://www.biotaneotropica.org.br 


\section{INTRODUÇÃO}

Muitos trabalhos nas regiões tropicais têm encontrado maior riqueza e abundância de borboletas em áreas perturbadas, o que tem sido atribuído a características específicas desses ambientes que poderiam favorecer tanto algumas espécies do ambiente original quanto espécies invasoras (e.g. Brown \& Hutchings 1997, DeVries \& Walla 2001). Dessa forma, enquanto algumas espécies de fato desaparecem de um sistema perturbado, outras podem ter suas populações muito aumentadas (Brown \& Hutchings 1997, DeVries \& Walla 2001). O monitoramento das populações e comunidades dessas espécies de borboletas ao longo do tempo pode fornecer informações importantes para que medidas sejam tomadas antes que os efeitos da perturbação ambiental sejam irreversíveis.

Apesar do crescente interesse de pesquisadores pela área de conservação e monitoramento ambiental, o "material base" do conhecimento para este tipo de trabalho (listas locais e regionais) ainda é escasso em muitos grupos, inclusive para borboletas (Brown \& Freitas 1999). Nos últimos anos, um número pequeno de inventários de borboletas dentro de biomas no domínio atlântico apareceu na literatura (Brown 1992, Mielke 1996, Mielke \& Casagrande 1998, Francini \& Freitas 1999, Brown \& Freitas 2000a, Motta 2002), e alguns trabalhos tem sido desenvolvidos em grupos de pesquisa do Rio Grande do Sul (PUC, UFRGS, UNIJUÍ), somando-se às já disponíveis até o momento (ver relação relativamente completa em Brown \& Freitas 1999, 2000b).

Recentemente, o programa BIOTA-FAPESP (http:// www.biota.org.br/) tem ajudado a suprir a carência de guias populares, financiando projetos diretamente ligados ao inventário da biodiversidade no Estado de São Paulo, e muitas listas regionais foram publicadas ou já estão disponíveis no sistema SinBiota (http://sinbiota.cria.org.br).

\subsection{Borboletas da Mata Atlântica}

A região da Mata Atlântica possui uma fauna de borboletas muito diversa, representando cerca de 2/3 das espécies brasileiras, muitas das quais raras e difíceis de encontrar (Brown 1996). Ao contrário da maioria das espécies da Floresta Amazônica, cujos habitats permanecem relativamente íntegros, grande parte das populações de borboletas da Mata Atlântica encontra-se hoje em fragmentos menores que 1.000 ha (Brown 1996; Brown \& Freitas 2000a, b). Nesses ambientes complexos e variáveis, a instabilidade local das populações é muito alta fazendo com que as comunidades de borboletas estejam sempre em fluxo, tipicamente com até metade das espécies locais tendo presença errática nos fragmentos menores (Brown \& Freitas 1999, 2000b, 2003).

Em 1997, no início do projeto "Lepidoptera do Estado de São Paulo: diversidade, distribuição, recursos, e uso em análise e monitoramento ambiental" (Biota-Fapesp, processo 98/05101-8), um total de 1.538 espécies de borboletas haviam sido registradas para o estado de São Paulo (Brown \& Freitas 1999). Até o momento, esse número já superou 1.600 espécies e continua aumentando lentamente, à medida que novas ocorrências são registradas e novas espécies são descobertas. Os padrões de distribuição geográfica de muitas borboletas da Mata Atlântica de São Paulo estão em parte elucidados, como resultado dos extensos inventários realizados no estado ao longo do último século por vários lepidopterologistas, e nos últimos anos pelo grupo de pesquisas de Lepidoptera ligado à Unicamp (Brown \& Freitas 1999, 2000b; Francini \& Freitas 1999). No entanto, para muitas espécies ainda existe pouca ou nenhuma informação sobre aspectos tão gerais como ciclo de vida, plantas hospedeiras, morfologia, sistemática, ecologia química, comportamento, ecologia de populações e uso do habitat. Infelizmente, segundo Brown \& Freitas (1999), grandes áreas do interior do estado, com alta diversidade genética, algumas certamente ainda abrigando espécies ameaçadas, poderão se tornar "desconhecíveis" (ou seja, destruídas antes de conhecidas) com relação à comunidade de borboletas, devido à conversão quase total da vegetação original em sistemas agro-industriais, queimados, poluídos e muito pobres em diversidade biológica (o que já é verdade para extensas áreas no noroeste do Estado).

Do total de borboletas registradas para o estado, aproximadamente 350 das 550 espécies de Nymphalidae, Papilionidae e Pieridae ("NPP"), são exclusivas ou apresentam parte da área de ocorrência na Mata Atlântica sensu strictu (K.S. Brown Jr. e A.V.L. Freitas, dados não publicados). As borboletas dessas famílias estão entre as mais estudadas, são relativamente fáceis de reconhecer no campo, e portanto são muito úteis na elaboração de inventários locais não destrutivos. Adicionalmente, alguns subgrupos de Nymphalidae (Satyrinae, Biblidinae e Charaxinae) são bons previsores da fauna total de borboletas em Mata Atlântica (Brown \& Freitas 2000b), e constituem opções adequadas para o estudo ao longo do tempo, espaço e em gradientes de perturbação (DeVries \& Walla 2001, e referências incluídas), podendo ser aplicados satisfatoriamente em programas de monitoramento ambiental (Freitas et al. 2003), fato que constitui um dos elementos vitais a qualquer programa de conservação (Kremen et al. 1994).

\subsection{Borboletas frugívoras}

Borboletas podem ser separadas basicamente em duas guildas, quando considerado o modo de alimentação dos adultos (DeVries 1987): 1 - borboletas que se alimentam de néctar: Papilionidae, Pieridae, Lycaenidae, Hesperiidae e as 
subfamílias de Nymphalidae, Libytheinae, Danainae, Ithomiinae, Heliconiinae e Nymphalinae; 2 - borboletas Nymphalidae, pertencentes à linhagem satiróide (sensu Freitas \& Brown 2004), que se alimentam de frutas fermentadas, excrementos, exudatos de plantas e animais em decomposição: Satyrinae, Brassolinae, Morphinae, Charaxinae, Biblidinae, e a tribo Coloburini (Nymphalinae).

Algumas espécies de Nymphalidae, pertencentes a guilda de borboletas que se alimentam de néctar, como Apaturinae, Limenitidinae e alguns Ithomiinae são eventualmente capturadas em iscas fermentadas (DeVries et al. 1999, Uehara-Prado 2003). Por fazer parte de outra guilda, e sofrer influência da presença de flores próximas às armadilhas, tais espécies não foram consideradas neste trabalho.

A amostragem de borboletas frugívoras apresenta algumas vantagens práticas, que facilitam o estudo de suas populações. Elas são facilmente capturadas em armadilhas contendo isca de fruta fermentada, de modo que a amostragem pode ser simultânea e o esforço pode ser padronizado em diferentes áreas e meses do ano (DeVries \& Walla 2001, e referências incluídas). Os indivíduos podem ser marcados e soltos depois de identificados, com um mínimo de manuseio, permitindo que um estudo não destrutivo seja efetuado com confiança. Ademais, a atração da borboleta pela isca, um recurso alimentar, reduz a possibilidade de capturas ao acaso, presentes em outros métodos (DeVries et al., 1999, DeVries \& Walla 2001, Freitas et al. 2003)

Guias ilustrados de borboletas, bem como de qualquer outro artrópode, são raros no Brasil. Atualmente, existem apenas três publicações deste tipo para borboletas, uma sobre as borboletas da Serra do Japi, SP (Brown 1992, com ilustração de mais de 600 espécies), uma sobre os Papilionidae das Américas (Tyler et al. 1994), e outra sobre as borbletas do Alto Rio Juruá, AC (Raimundo et al. 2003), além de algumas publicações gerais sobre ciclo de vida e comportamento de borboletas (Otero 1986, Otero \& Marigo 1990, 1992). Segundo Lewinsohn \& Prado (2002: 101), a produção de guias de campo para grupos com taxonomia mais resolvida está entre as ações prioritárias para o maior conhecimento da biodiversidade brasileira.

O presente trabalho vem ao encontro das necessidades apresentadas nesta seção introdutória, servindo ao mesmo tempo como guia de campo para lazer (ecoturismo, observação de borboletas), educação, e para monitoramento ambiental.

\section{MÉTODOS}

\section{1 Áreas de estudo}

A área de estudo está localizada no distrito de Caucaia do Alto, município de Cotia, Estado de São Paulo (233' 'S $\left.23^{\circ} 50^{\prime} \mathrm{S}, 46^{\circ} 45^{\prime} \mathrm{W}-47^{\circ} 15^{\prime} \mathrm{W}\right)$. A altitude na região varia de 800 a 1.000 metros, e o clima é temperado chuvoso, macrotérmico de inverno seco, do tipo Cwa segundo classificação de Köppen (1948), com temperaturas médias mensais variando entre $11^{\circ} \mathrm{C}$ e $27^{\circ} \mathrm{C}$, e média de precipitação de 1.400 mm (SABESP 1997). As matas originais da região foram definidas, segundo Veloso et al. (1991), como floresta ombrófila densa.

Na região de estudo encontra-se a Reserva Estadual

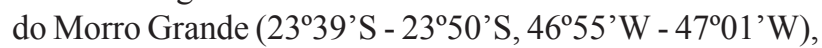
uma das maiores áreas de mata fora das encostas das serras litorâneas. A reserva possui mais de 10.000 ha, grande parte em estágios avançados de sucessão, contendo também áreas bem preservadas de floresta nativa. Na paisagem fragmentada, a matriz é composta essencialmente por pequenos pomares, horticulturas e chácaras. Em alguns locais as áreas agrícolas misturam-se à matas em estágios iniciais de regeneração (2 a 8 anos) e com reflorestamentos de Eucalyptus e Pinus. Uma interpretação de fotografias aéreas (pares estereoscópicos) de abril de 2000, na escala 1:10.000, mostrou que a paisagem fragmentada ainda possui cerca de $35 \%$ de vegetação natural, na sua maioria em estágios iniciais e intermediários de regeneração (J. P. Metzger, dados não publicados).

\subsection{Amostragem}

Este guia foi elaborado a partir da lista total de espécies de borboletas frugívoras da Reserva Estadual do Morro Grande e da paisagem fragmentada de Caucaia do Alto, Município de Cotia (SP). As borboletas foram amostradas através de levantamentos maximizados e amostragem padronizada com armadilhas. Nos levantamentos maximizados, um ou mais pesquisadores percorriam diversos ambientes em diferentes horas do dia, procurando ativamente adultos, formas imaturas ou qualquer vestígio (pedaços de asa, teias produzidas por larvas) que possibilitasse a identificação de espécies de borboletas. As amostragens foram realizadas com rede entomológica, armadilhas de diferentes modelos, com diferentes iscas (como peixe em decomposição, excrementos de animais, abacaxi) e visualizações ocasionais, num total de 100 horas efetivas. A amostragem padronizada foi feita com armadilhas modelo Van Someren-Rydon (detalhes em Shuey 1997) em quatro áreas diferentes da Reserva do Morro Grande e em cinco fragmentos florestais, totalizando 800 horas efetivas de amostragem. Antes de ser solta, cada borboleta capturada nas armadilhas recebeu uma marca alfanumérica individualizada na face ventral das asas anteriores. Maiores detalhes quanto a características das áreas e o método de amostragem por armadilhas podem ser encontrados em Uehara-Prado (2003). Informações sobre o procedimento dos inventários maximizados são detalhadas em Brown 
(1972), Brown \& Hutchings (1997), Brown \& Freitas (1999) e Freitas et al. (2003).

\subsection{Estrutura do guia e informações adicionais}

A nomenclatura taxonômica para Nymphalidae segue Harvey (1991) modificado por Freitas \& Brown (2004). A lista de todas as espécies de borboletas frugívoras com sua distribuição geográfica aproximada está no apêndice 1. Não foram consideradas na listagem duas espécies de Brassolinae (Dynastor darius e Brassolis sophorae) por não se alimentarem na fase adulta, e três de Morphinae (Morpho hercules, $M$. aega e $M$. anaxibia, que estão ilustradas em Brown 1992, prancha 8.4) por serem muito raramente atraídas a frutos e conseqüentemente quase ausentes em armadilhas.

Dezoito pranchas coloridas compõem o guia. A posição na prancha, ventral ou dorsal, está indicada logo abaixo de cada espécime, como (V) e (D), respectivamente. Quando fêmeas de uma espécie foram ilustradas, o símbolo 千 foi usado abaixo do exemplar. As borboletas estão com $87 \%$ do tamanho original, exceto nas pranchas 5 e 6 onde as imagens são $56 \%$ do tamanho original (devido ao tamanho grande dos indivíduos).

\section{AGRADECIMENTOS}

A SABESP, na pessoa do Eng ${ }^{\circ}$ José Roberto Náli, e ao Instituto Florestal SP, pelas facilidades oferecidas ao longo do estudo. Ao Prof. Dr. Jean Paul Metzger, principal responsável pela realização deste trabalho integrando dois projetos temáticos do programa Biota Fapesp. Ao Muzeu de Zoologia da Usp, na pessoa do Dr. Marcelo Duarte, pelo apoio nas visitas à coleção para fotografar alguns dos espécimes ilustrados no guia. Dois assessores anônimos contribuíram com importantes correções e sugestões para a versão final deste trabalho. Esta pesquisa fez parte dos projetos temáticos "Consevação da Biodiversidade em Paisagens Fragmentadas no Planalto Atlântico de São Paulo" (Fapesp n. 99/05123-4, publicação no 2) e "Lepidoptera do Estado de São Paulo: diversidade, distribuição, recursos, e uso em análise e monitoramento ambiental" (Fapesp n. 98/05101-8). MU-P e AVLF agradecem à Fapesp pelos auxílios recebidos no período do estudo (00/14717-4 e 00/01484-1, respectivamente).

\section{REFERÊNCIAS BIBLIOGRÁFICAS}

BROWN JR., K.S. 1972. Maximizing daily butterfly counts. J. Lepid. Soc. 26: 183-196.
BROWN JR., K.S. 1992. Borboletas da Serra do Japi: diversidade, habitats, recursos alimentares e variação temporal. In História Natural da Serra do Japi: ecologia e preservação de uma área florestal no Sudeste do Brasil (L.P.C. Morellato, org.). Editora Unicamp, Campinas, p.142-186.

BROWN JR., K.S. 1996. Conservation of threatened species of Brazilian butterflies. In Decline and conservation of butterflies in Japan (Ae, S.A., T. Hirowatari, M. Ishii \& L.P. Brower, eds.). Yadoriga special issue. Lepidopterist Society of Japan, Osaka, p.45-62.

BROWN JR., K.S. \& FREITAS, A.V.L. 1999. Lepidoptera. In Biodiversidade do Estado de São Paulo, Brasil: síntese do conhecimento ao final do século XX. V. 5 Invertebrados terrestres (C.R.F. Brandão \& E.M. Cancello eds.) C.A. Joly e C.E.M. Bicudo (orgs). - São Paulo: FAPESP, 1999, p. 225-243.

BROWN JR., K.S. \& FREITAS, A.V.L. 2000a. Diversidade de Lepidoptera em Santa Teresa, Espírito Santo. Bol. Mus. Biol. Mello Leitão (N Sér.) 11/12: 71-116.

BROWN JR., K.S. \& FREITAS, A.V.L. 2000b. Atlantic Forest Butterflies: Indicators for Landscape Conservation. Biotropica 32: 934-956.

BROWN JR., K.S. \& FREITAS, A.V.L. 2003. Butterfly Communities of Urban Forest Fragments in Campinas, São Paulo, Brazil: Structure, Instability, Environmental Correlates, and Conservation. J. Insect Conserv. 6: 217-231.

BROWN JR., K.S. \& HUTCHINGS, R.W. 1997. Disturbance, fragmentation, and the dynamics of diversity in Amazonian butterflies. In Tropical forest remnants (W.F. Laurence \& R.O. Bierregaard Jr., eds.). University of Chicago Press, Chicago, p.91-110.

DEVRIES, P.J. 1987. The butterflies of Costa Rica and their natural history: Papilionidae, Pieridae, and Nymphalidae. Princeton University Press, Princeton.

DEVRIES, P.J., WALLA, T.R. \& GREENEY,H.F. 1999. Species diversity in spatial and temporal dimensions of a fruit-feeding butterfly community from two Ecuadorian rainforest. Biol. J. Linnean. Soc. 68: 333-353.

DEVRIES, P.J. \& WALLA, T.R. 2001. Species diversity and community structure in neotropical fruit-feeding butterflies. Biol. J. Linnean. Soc. 74: 1-15.

FRANCINI, R.B. \& FREITAS, A.V.L.. 1999. Borboletas da Baixada Santista. URL: http://www.unisantos.com.br/ $\sim$ metropms/xixova/a.htm

FREITAS, A.V.L. \& BROWN JR., K.S. 2004. Phylogeny of the Nymphalidae (Lepidoptera). Syst. Biol., no prelo.

FREITAS, A.V.L., FRANCINI, R.B. \& BROWN JR., K.S. 2003. Insetos como indicadores ambientais. Capítulo 5 In Métodos de estudos em biologia da conservação e manejo da vida silvestre (L Cullen Jr., C. Valladares-Pádua \& R. Rudran, orgs.). Editora da UFPR, p. 125-151. 
HARVEY, D.J. 1991. Higher classification of the Nymphalidae. In The development and evolution of butterfly wing patterns. (H.F. Nijhout, ed.). Smithsonian Institution Press, Washington, DC, p.255-273.

KREMEN, C., MERENLENDER, A.M. \& MURPHY, D.D. 1994. Ecological monitoring: A vital need for integrated conservation and development programs in the tropics. Cons. Biol. 8: 388-397.

KÖPPEN, W. 1948. Climatologia. Fondo Cultura Economica, Pánuco.

LEWINSOHN, T.M \& PRADO, P.I. 2002. Biodiversidade brasileira: síntese do estado atual do conhecimento. Editora Contexto, São Paulo.

MIELKE, C.G.C. 1996. Papilionoidea e Hesperioidea (Lepidoptera) de Curitiba e seus arredores, Paraná, Brasil, com notas taxonômicas sobre Hesperiidae. Rev. Bras. Zool. 11:759-776.

MIELKE, O.H.H. \& CASAGRANDE, M.M. 1998. Papilionoidea e Hesperioidea (Lepidoptera) do Parque Estadual do Morro do Diabo, Teodoro Sampaio, São Paulo, Brasil. Rev. Bras. Zool. 14: 967-1001.

MOTTA, P.C. 2002. Butterflies from the Uberlândia region, Central Brazil: Species list and biological comments. Braz. J. Biol. 62: 151-163.

OTERO, L.S. 1986. Borboletas. Livro do Naturalista. Fundação de Assistência ao Estudante, Rio de Janeiro.

OTERO, L.S. \& MARIGO, L.C. 1990. Borboletas, beleza e comportamento das espécies brasileiras. Marigo Comunicação Visual, Rio de Janeiro.

OTERO, L.S. \& MARIGO, L.C 1992. Borboletas de Carajás. Butterflies of Carajás. Companhia Vale do Rio Doce, Rio de Janeiro.

RAIMUNDO, R.L.G., A.V.L. FREITAS, R.N.S. COSTA, J.B.F. OLIVEIRA, A.B. MELO \& K.S. BROWN JR. 2003. Manual de monitoramento ambiental usando borboletas e libélulas - Reserva Extrativista do Alto Juruá. Série Pesquisa e Monitoramento Participativo em Áreas de Conservação Gerenciadas por Populações Tradicionais, Volume 1. CERES/Laboratório de Antropologia e Ambiente, Campinas.

SABESP 1997. Programa de Conservação do Sistema Cotia. Relatório Conclusivo (tomo 3): Avaliação Ambiental. SABESP/Fundação Brasileira para o Desenvolvimento Sustentável, São Paulo.

SHUEY, J.A. 1997. An optimizing portable bait trap for quantitative sampling of butterflies. Trop. Lep. 8: 1-4.

TYLER, H.A., BROWN JR., K.S. \& WILSON, K.H. 1994. Swallowtail butterflies of the Americas. A study in biological dynamics, ecological diversity, biossystematics and conservation. Scientific Publishers, Gainesville.
UEHARA-PRADO, M. 2003. Efeito de fragmentação florestal na guilda de borboletas frugívoras do Planalto Atlântico Paulista. Dissertação de Mestrado, Universidade Estadual de Campinas, Campinas, São Paulo.

VELOSO, H.P., RANGEL FILHO, A.L.R. \& LIMA, J.C.A. 1991. Classificação da vegetação brasileira adaptada a um sistema universal. IBGE, Rio de Janeiro.

Título: Guia das borboletas frugívoras da reserva estadual do Morro Gande e região de Caucaia do Alto, Cotia (São Paulo)

Autores: Marcio Uehara-Prado, André Victor Lucci Freitas, Ronaldo Bastos Francini, Keith Spalding Brown Jr.

Biota Neotropica, Vol. 4 ( número 1): 2004

http://www.biotaneotropica.org.br/v4n 1/pt/ abstract?inventory+BN00504012004

Recebido em: 14/08/2003 - Revisado em: 26/01/2004

Publicado em: 12/02/2004

ISSN 1676-0603 


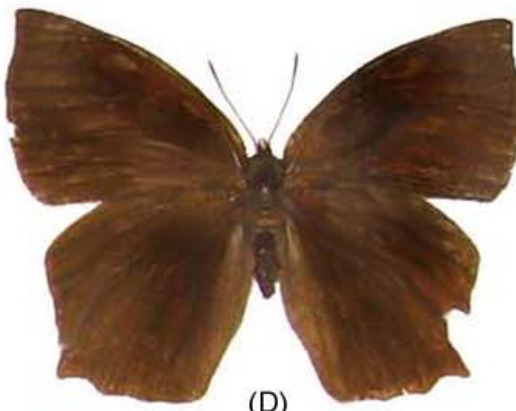

(D)

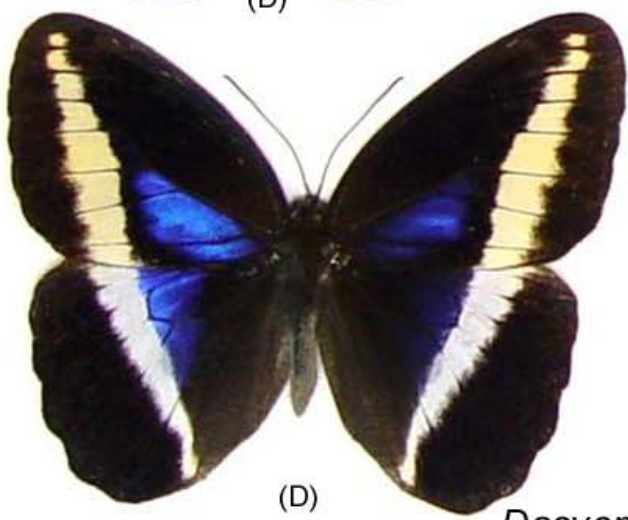

(D)

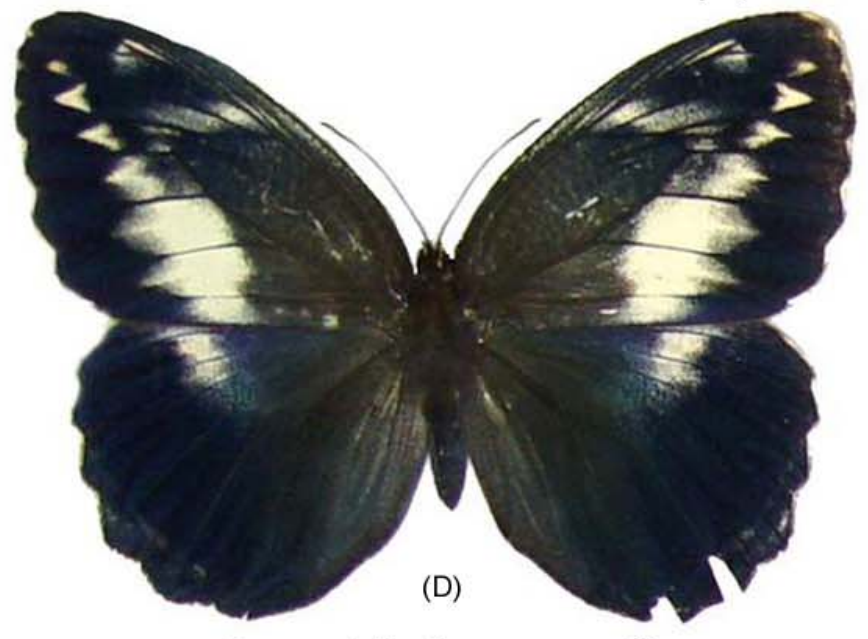

Dasyophthalma creusa 우

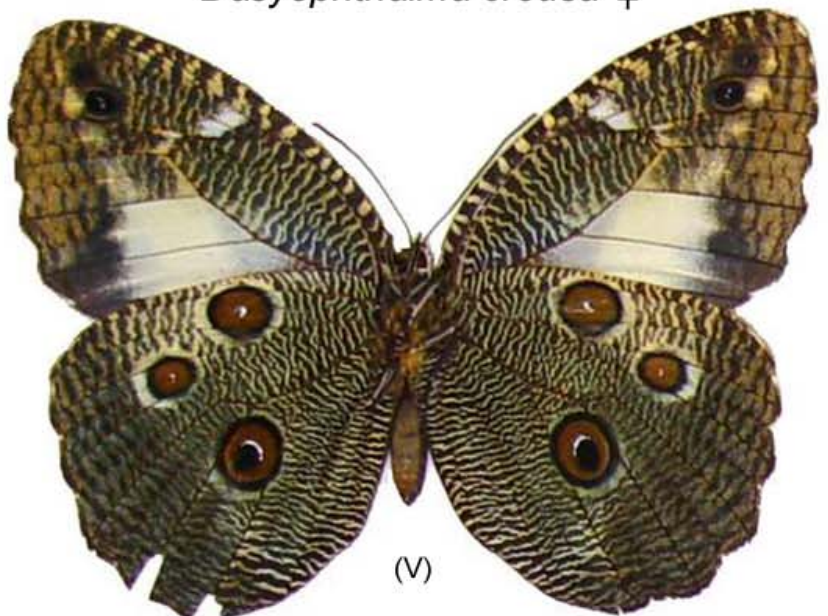

Prancha 1 - Brassolinae frugívoras da Reserva Estadual do Morro Grande e região de Caucaia do Alto, Cotia/SP, Brasil.
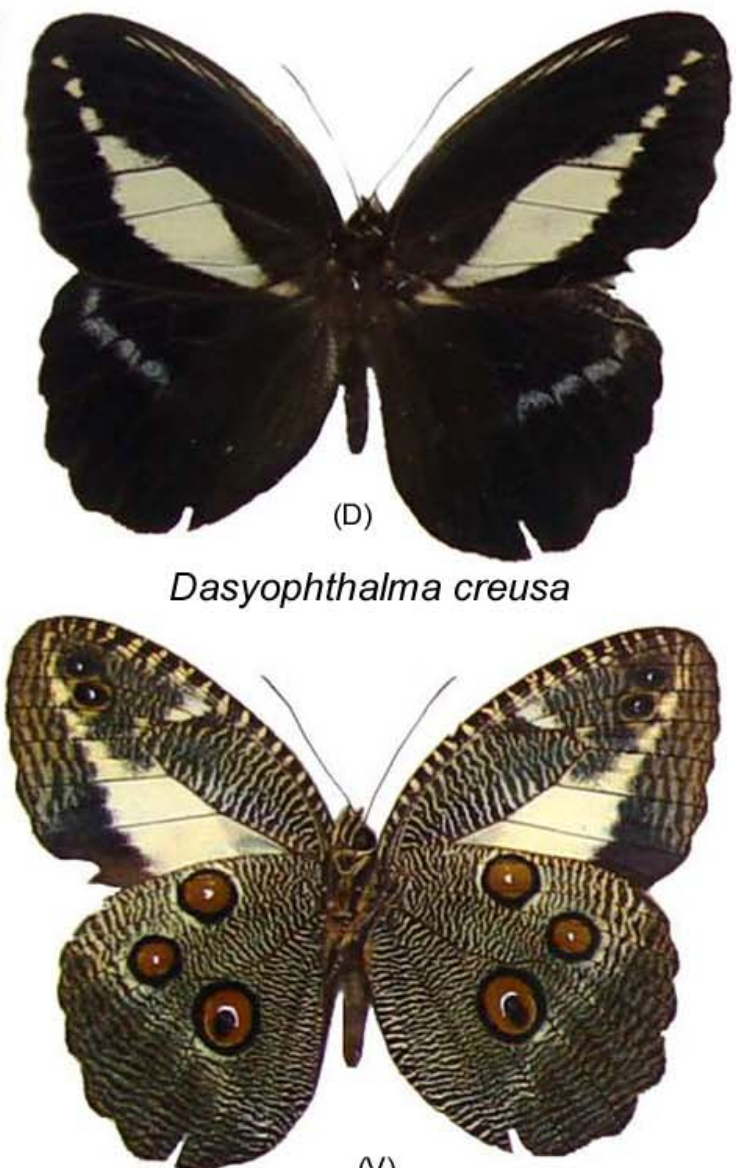

(v)
Dasyophthalma creusa

http://www.biotaneotropica.org.br 


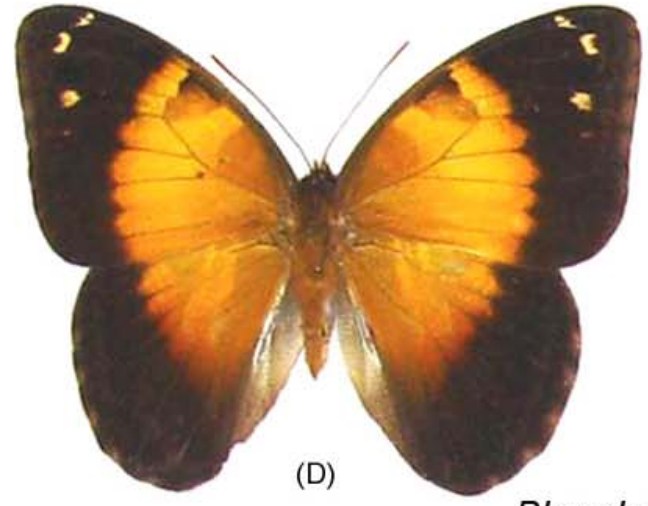

Blepolenis batea
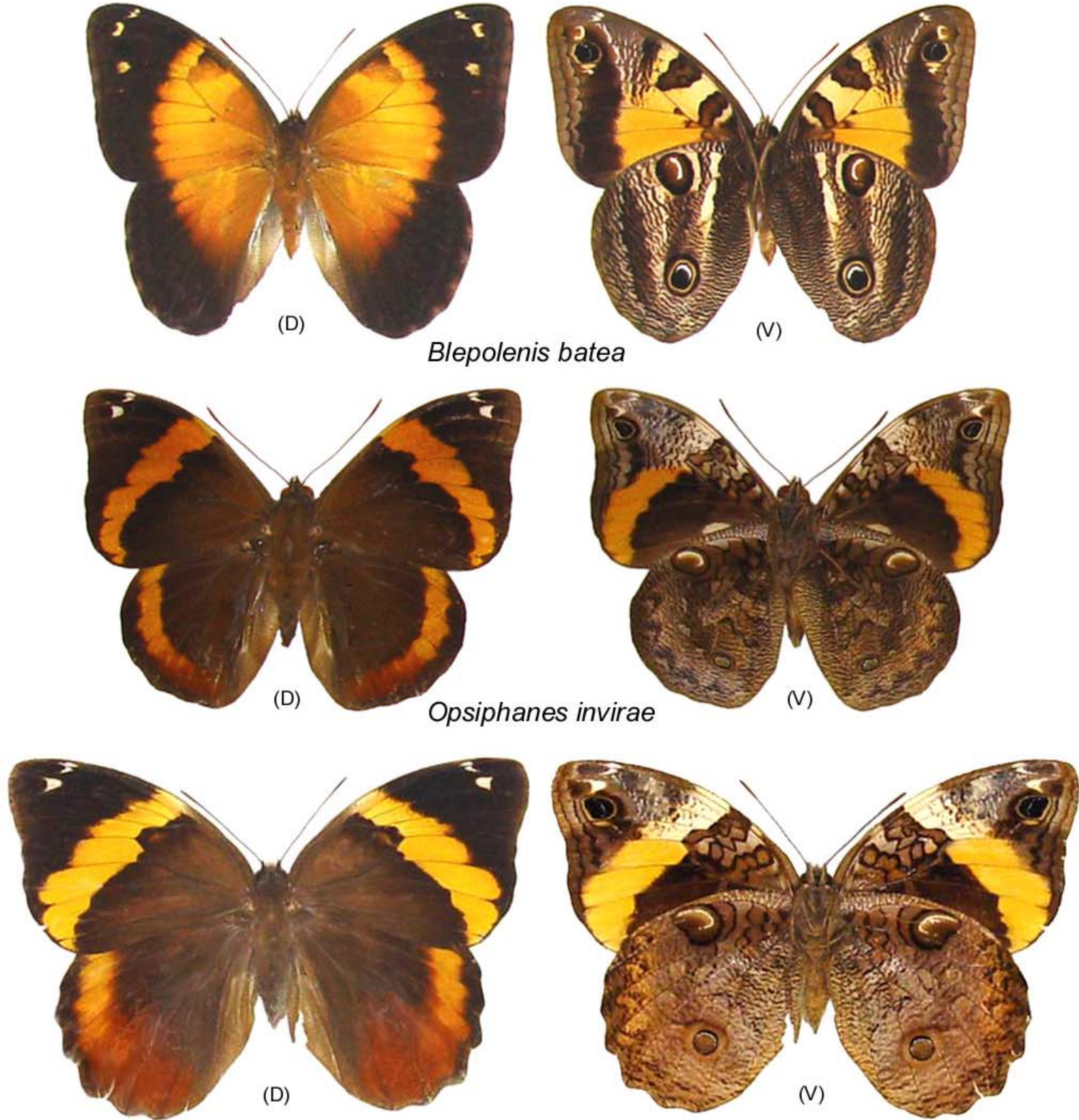

Opsiphanes invirae $q$
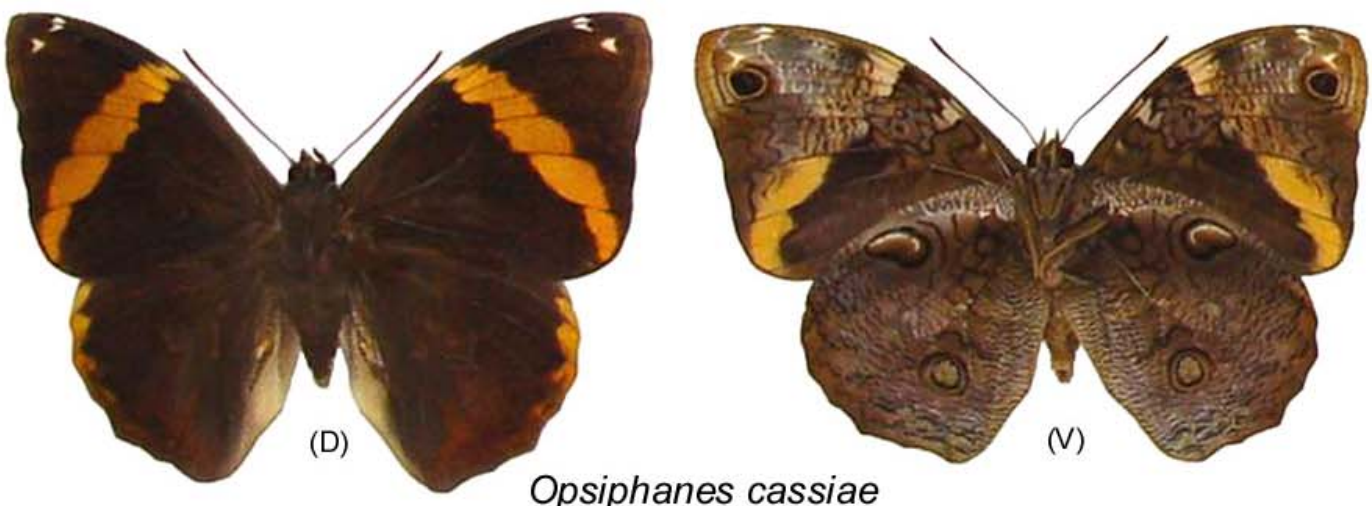

Prancha 2 - Brassolinae frugívoras da Reserva Estadual do Morro Grande e região de Caucaia do Alto, Cotia/SP, Brasil 

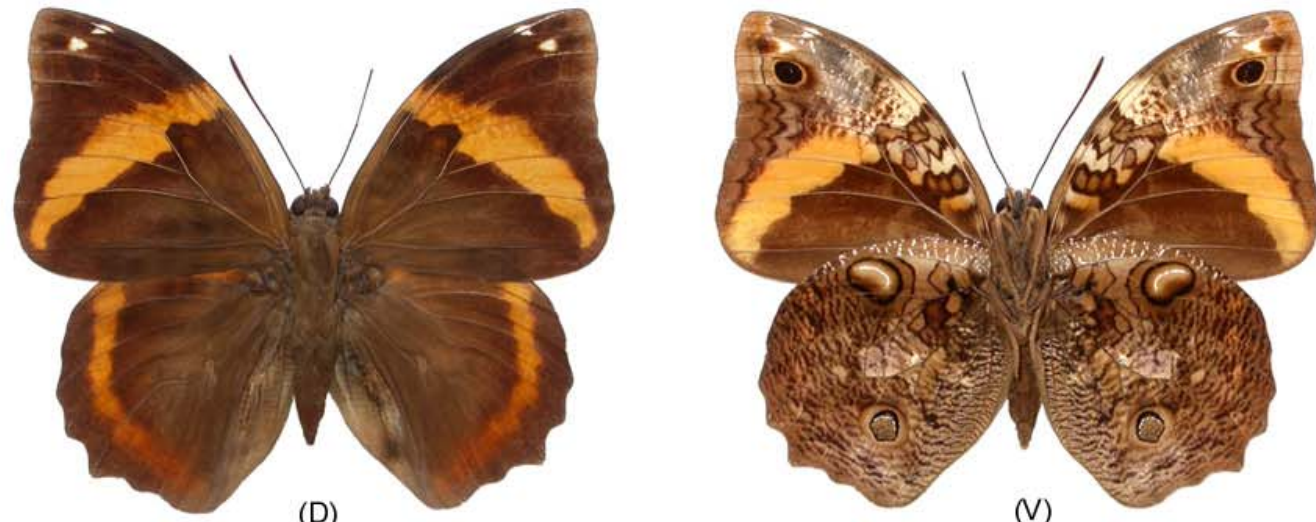

Opsiphanes quiteria
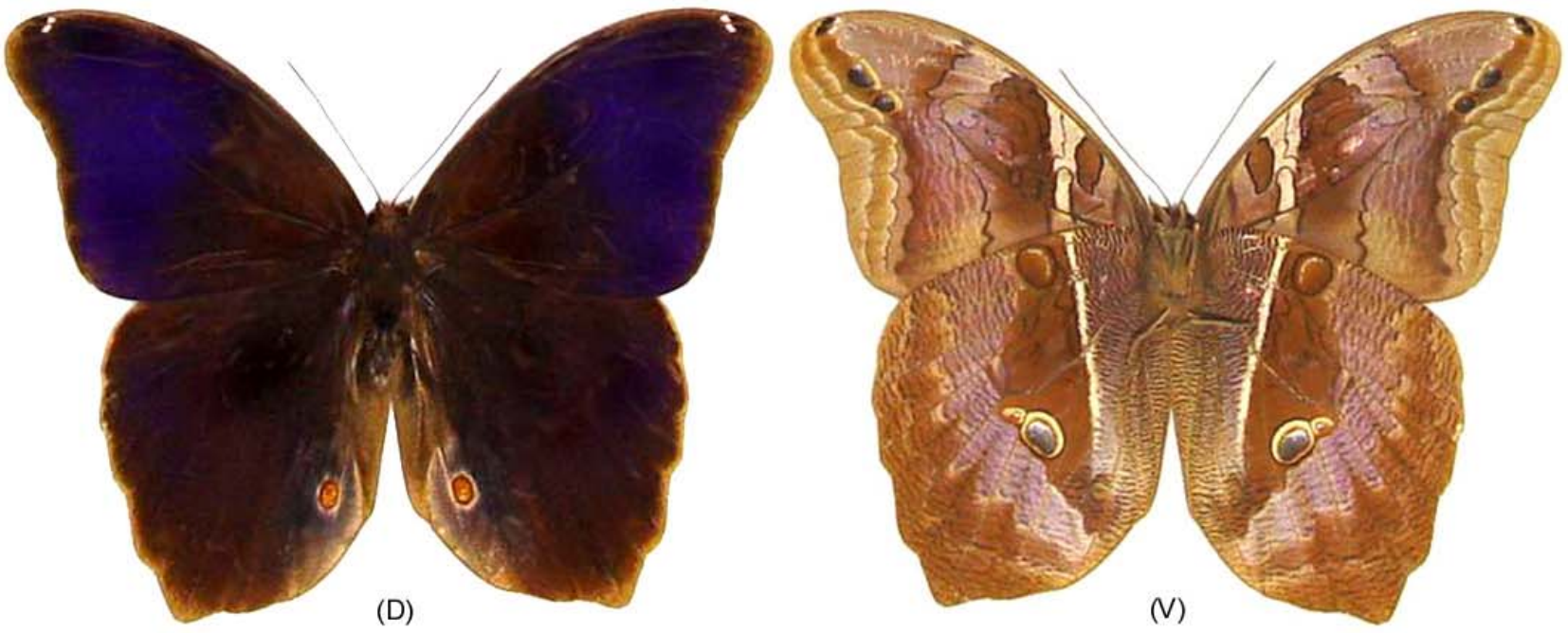

Eryphanis reevesi
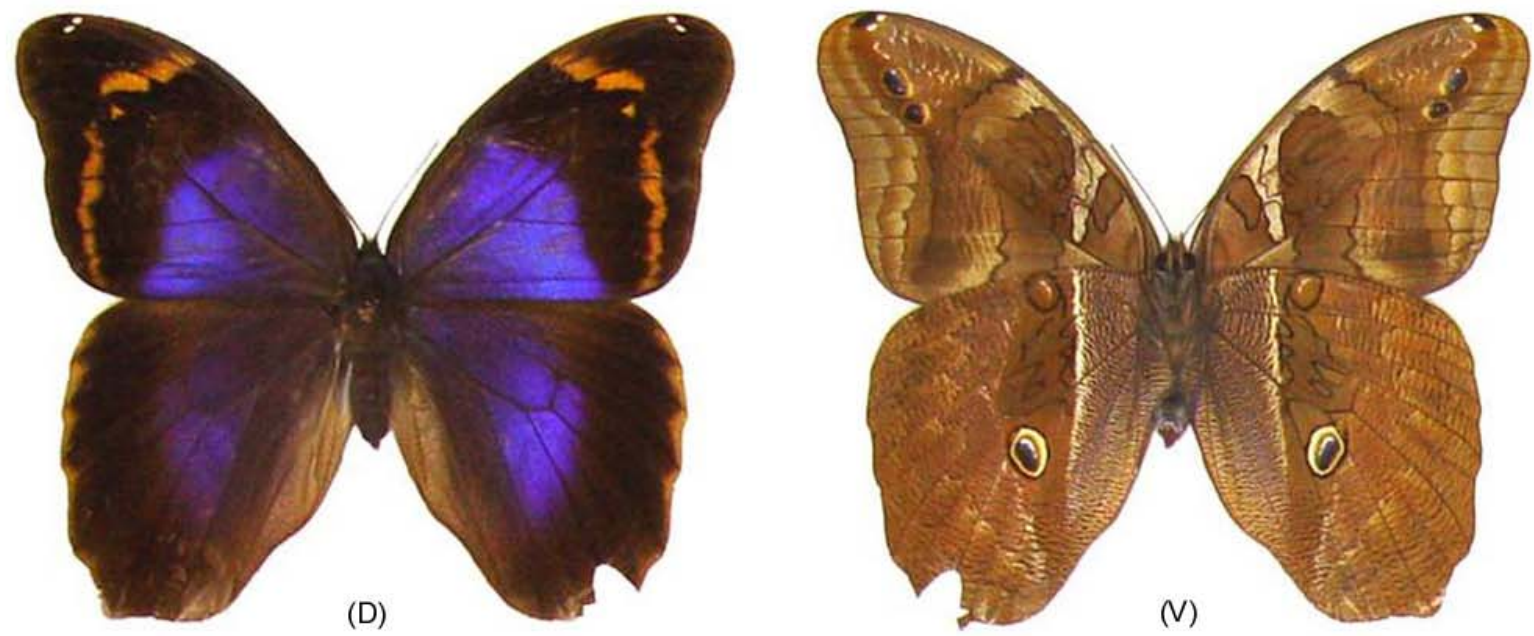

Eryphanis reevesi 우

Prancha 3 - Brassolinae frugivoras da Reserva Estadual do Morro Grande e região de Caucaia do Alto, Cotia/SP, Brasil 

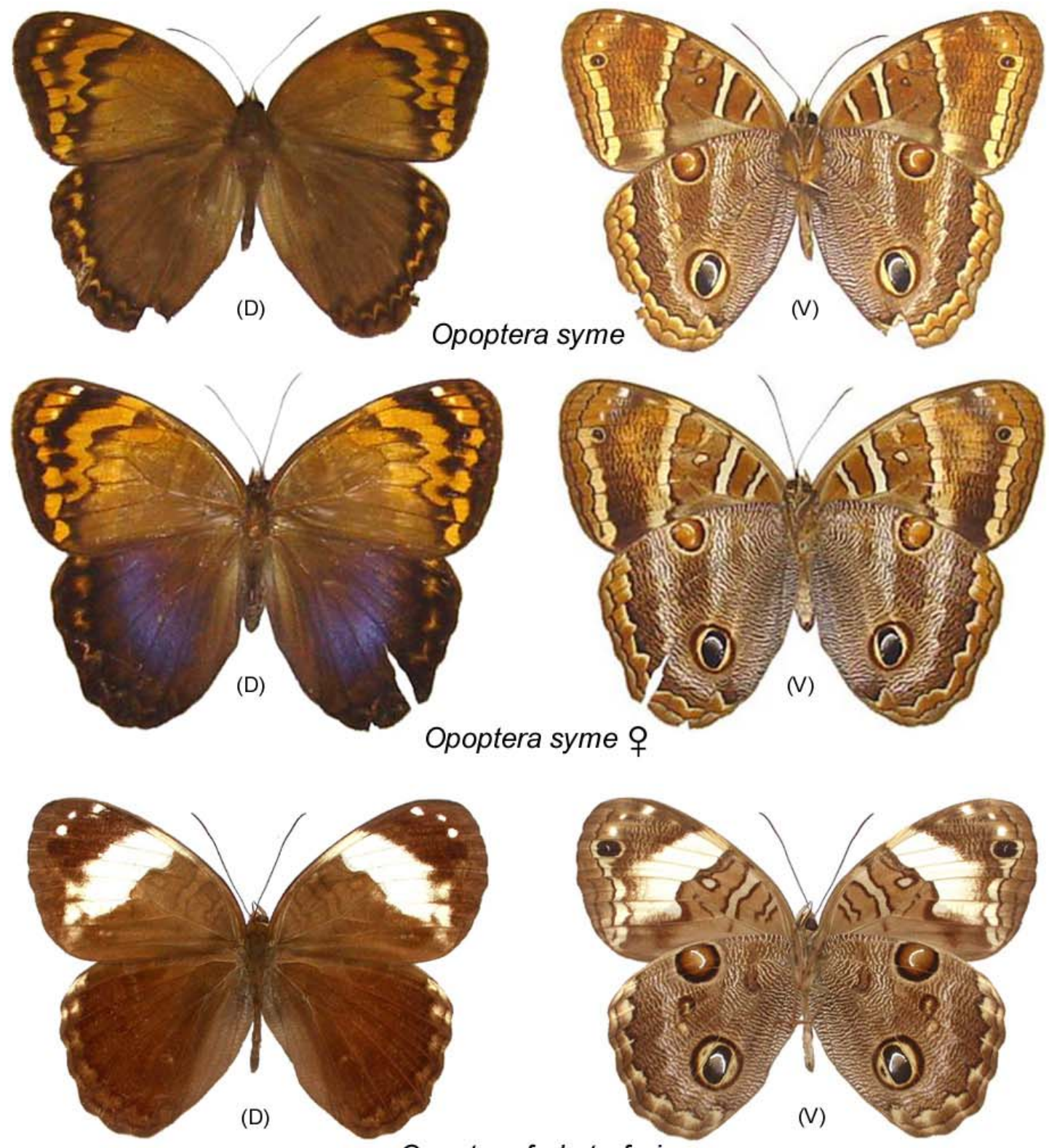

Opoptera fruhstorferi
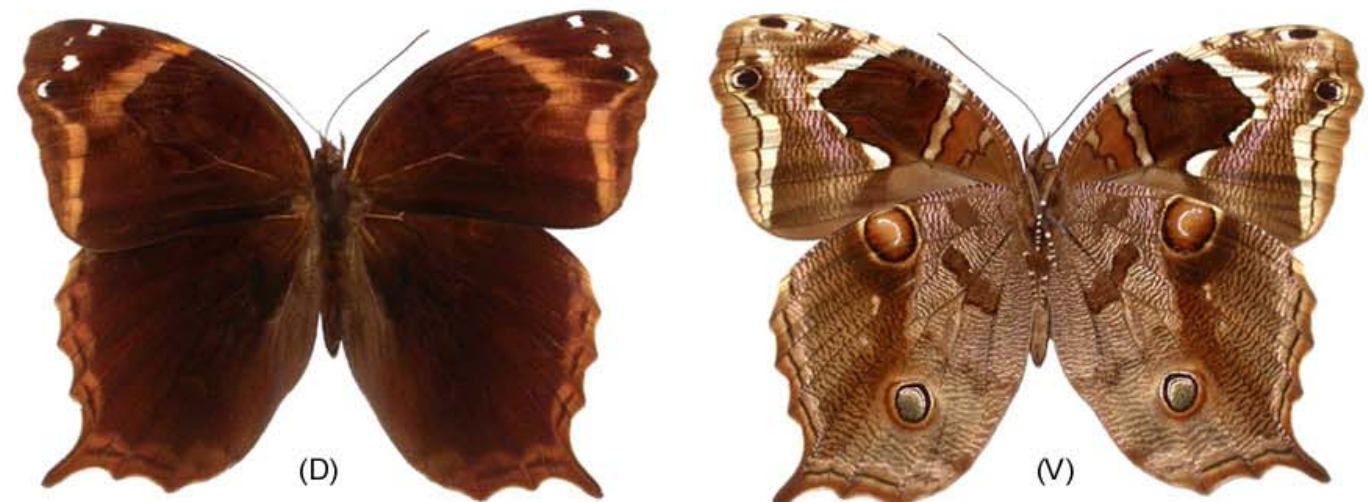

Opoptera aorsa

Prancha 4 - Brassolinae frugivoras da Reserva Estadual do Morro Grande e região de Caucaia do Alto, Cotia/SP, Brasil 


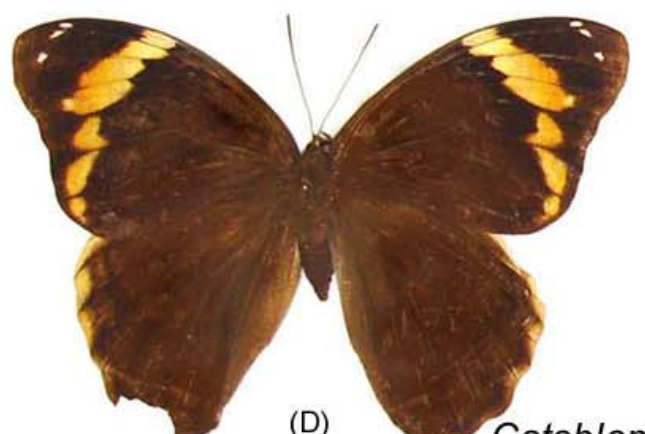

(D)

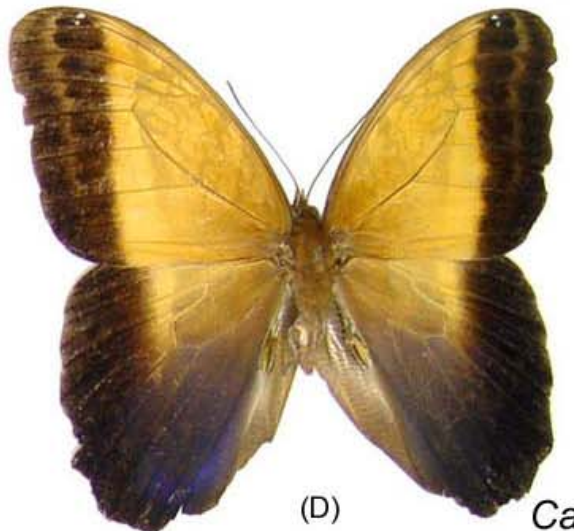

(D)

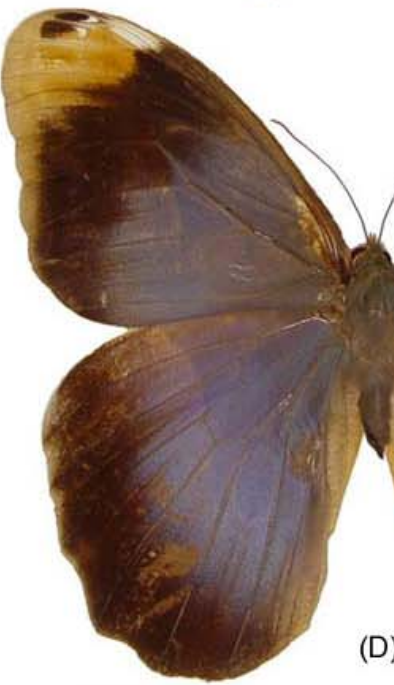

(D)

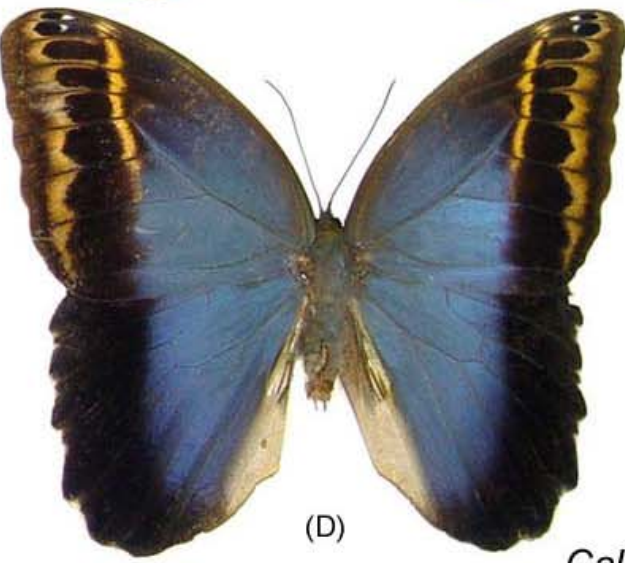

Caligo illioneus

Caligo beltrao

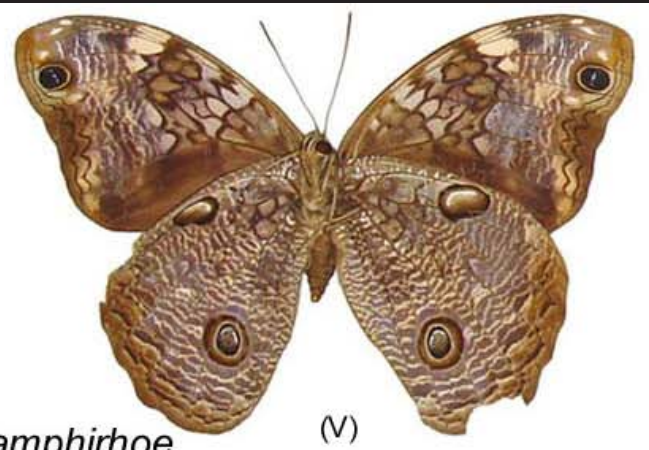

(V)
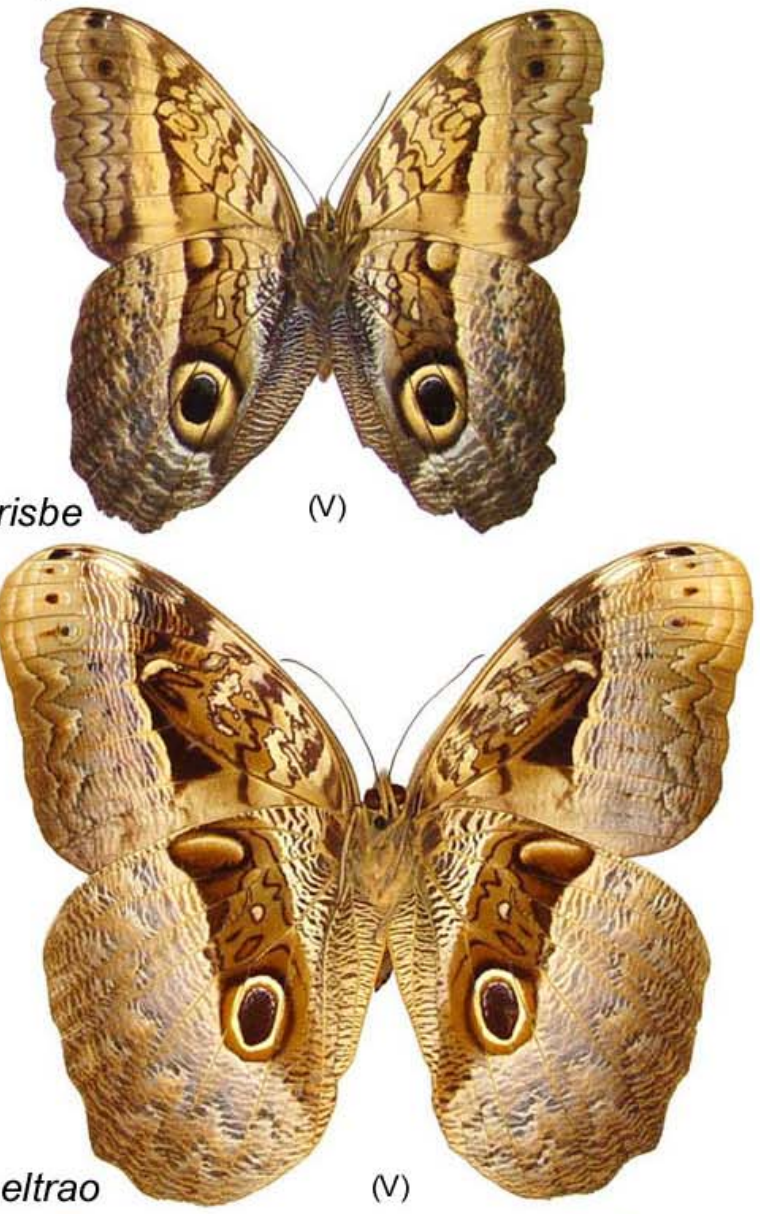

(V)

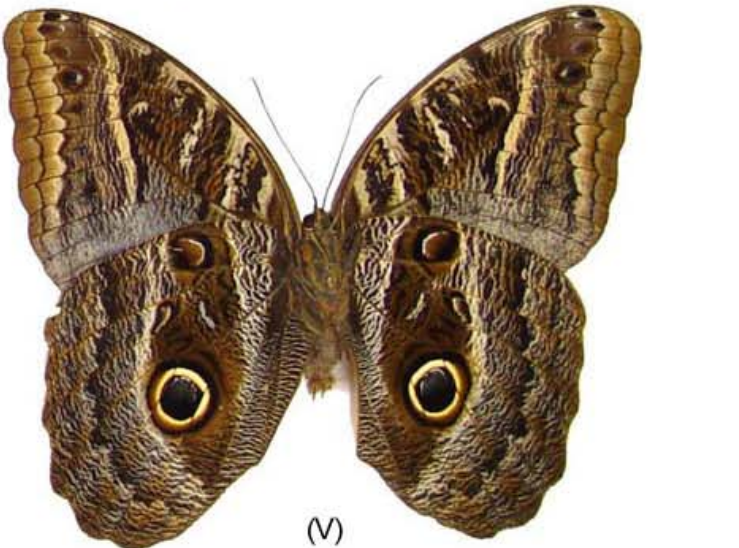

(V)

Prancha 5 - Brassolinae frugívoras da Reserva Estadual do Morro Grande e região de Caucaia do Alto, Cotia/SP, Brasil 

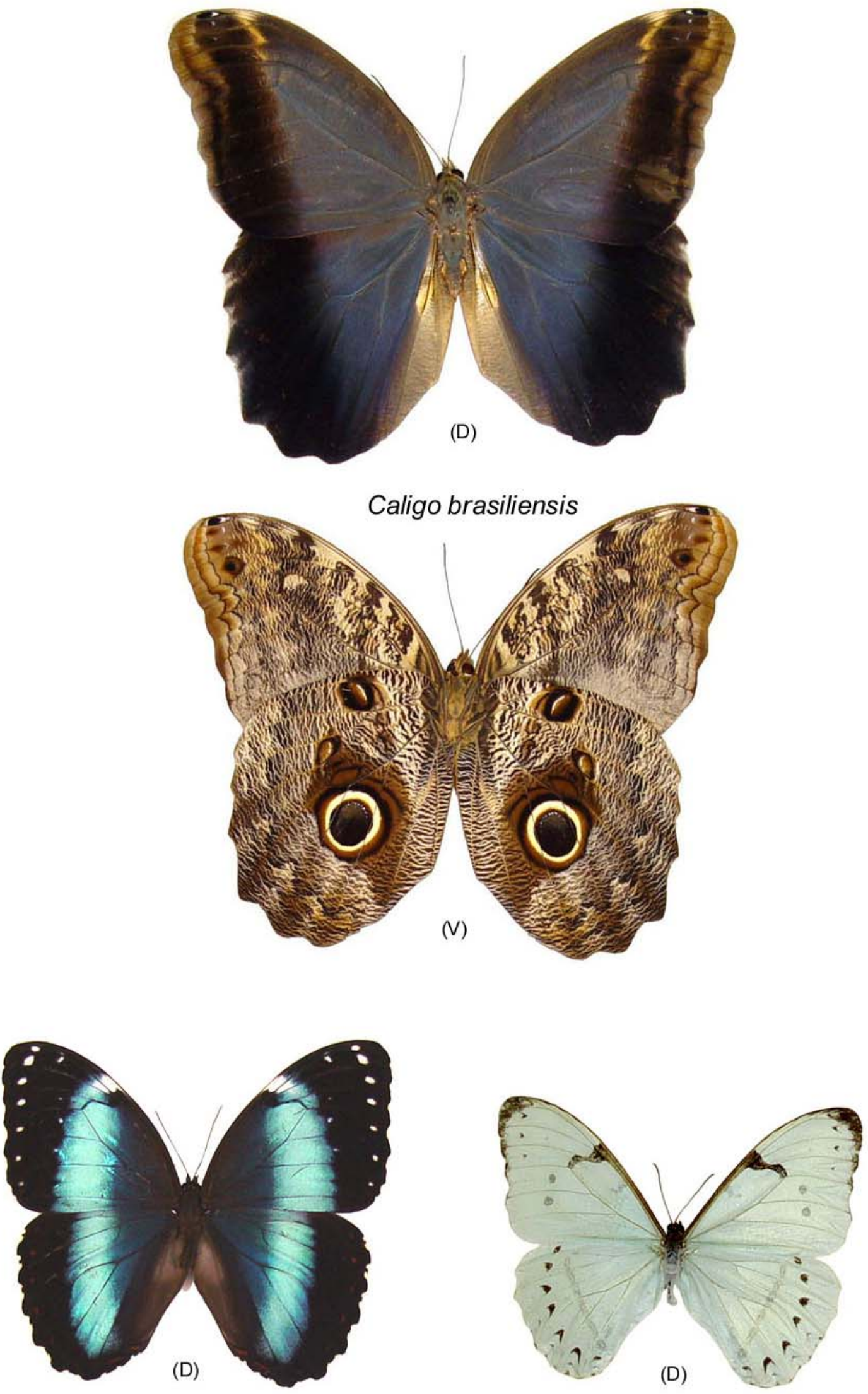

Morpho achilles

Morpho catenarius

Prancha 6 - Brassolinae/Morphinae frugívoras da Reserva Estadual do Morro Grande e região de Caucaia do Alto, Cotia/SP, Brasil 


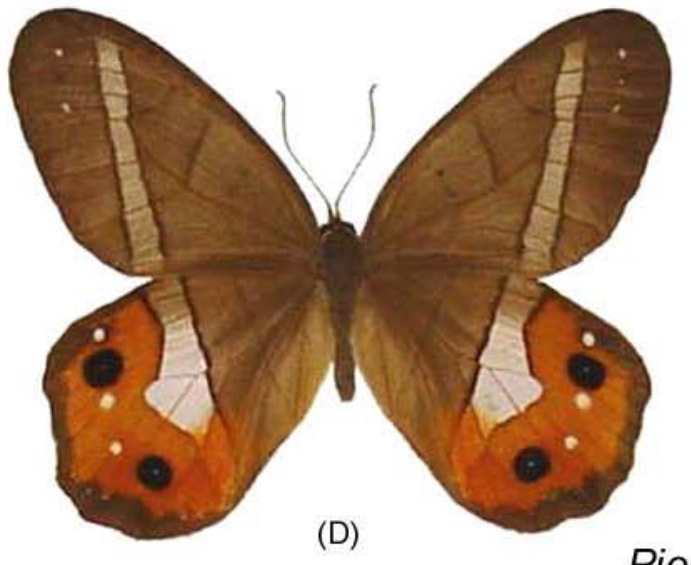

Pierella nereis

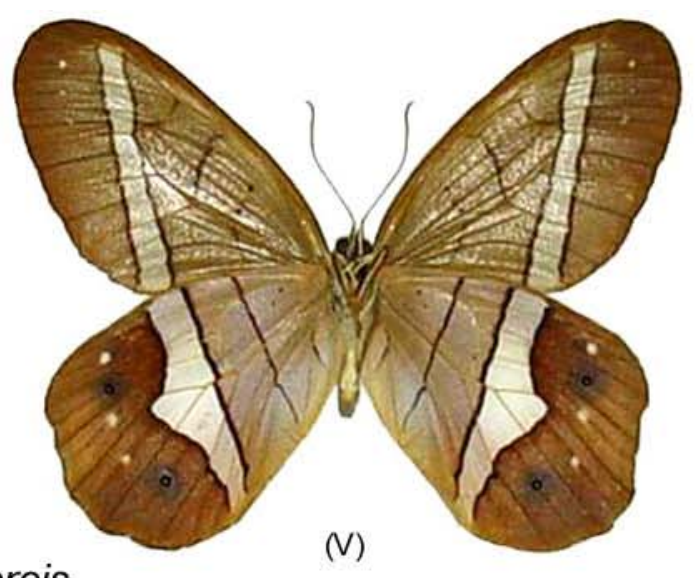

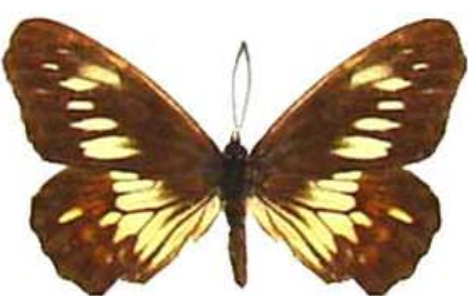

(D)

우

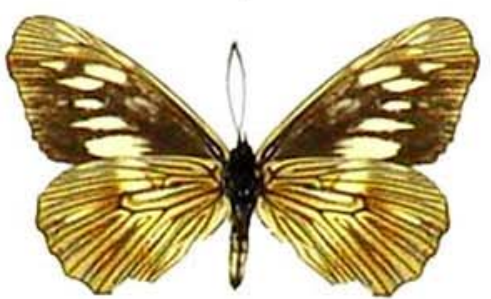

(V)

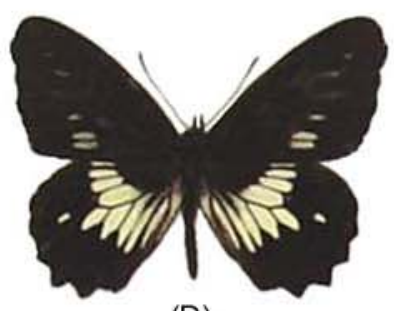

(D)

Eteona tisiphone

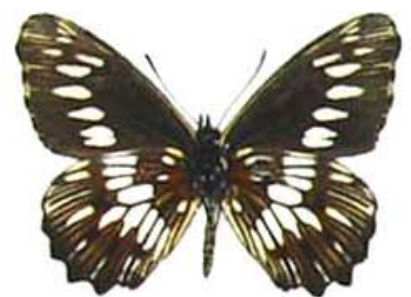

(V)

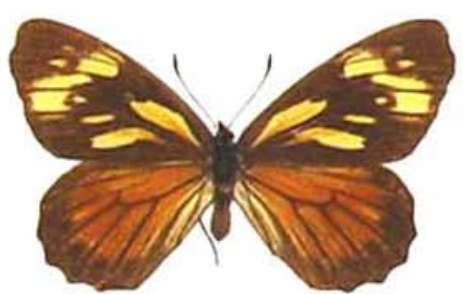

(D)

Q

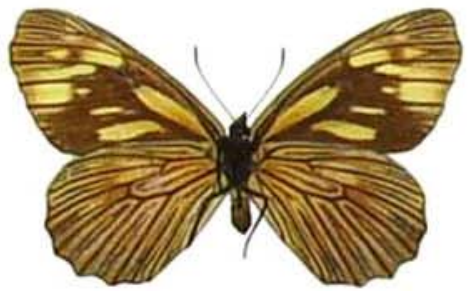

(V)

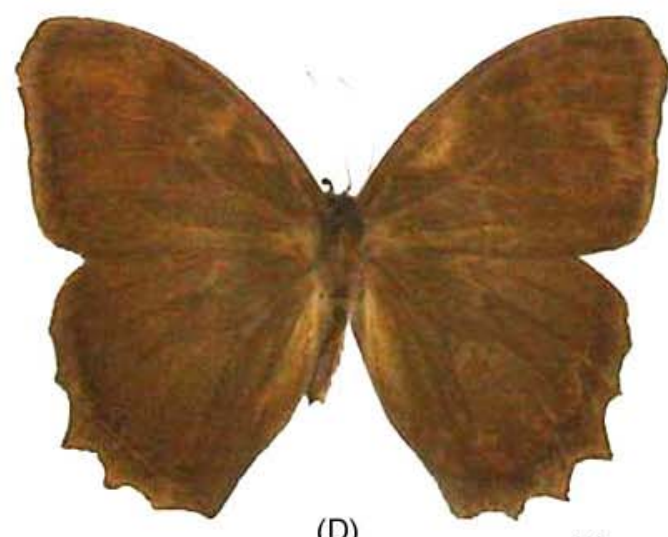

(D)

Taygetis laches

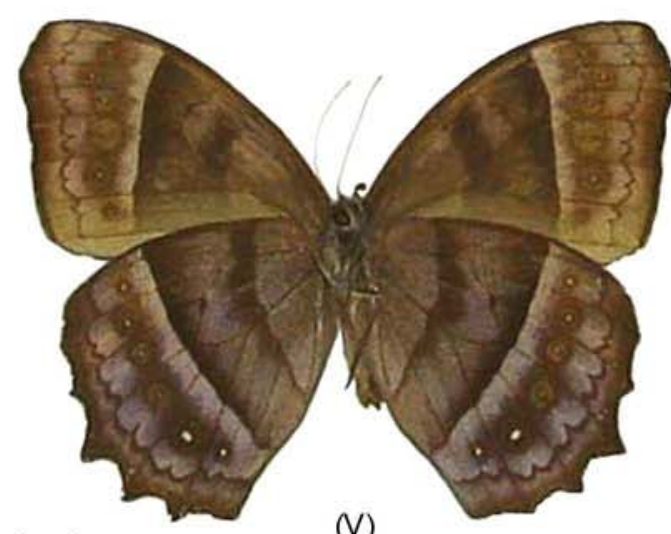

(V)

Prancha 7 - Satyrinae frugívoras da Reserva Estadual do Morro Grande e região de Caucaia do Alto, Cotia/SP, Brasil 


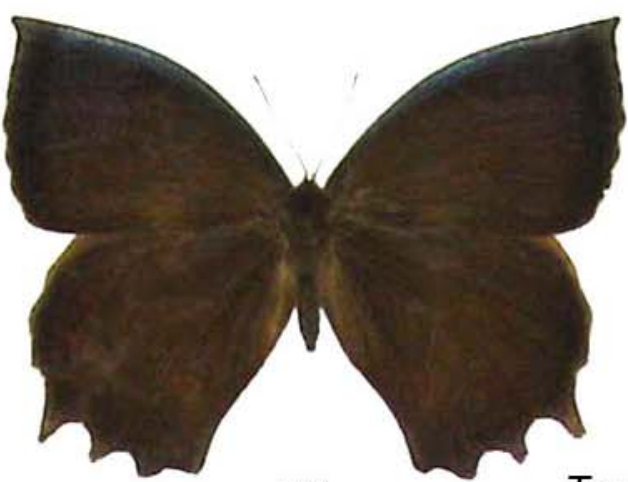

(D)

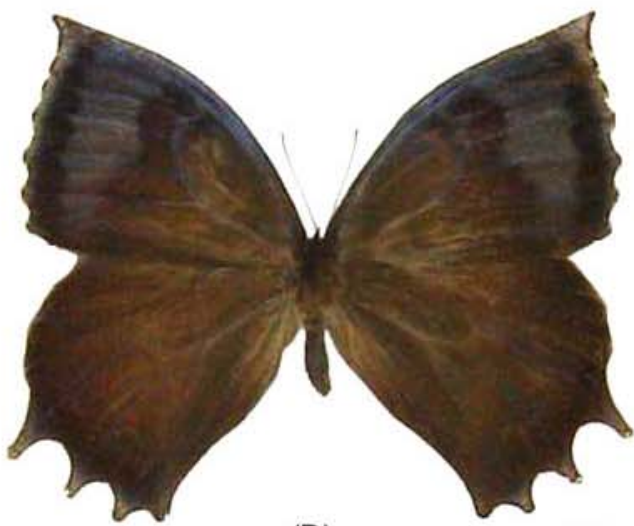

(D)

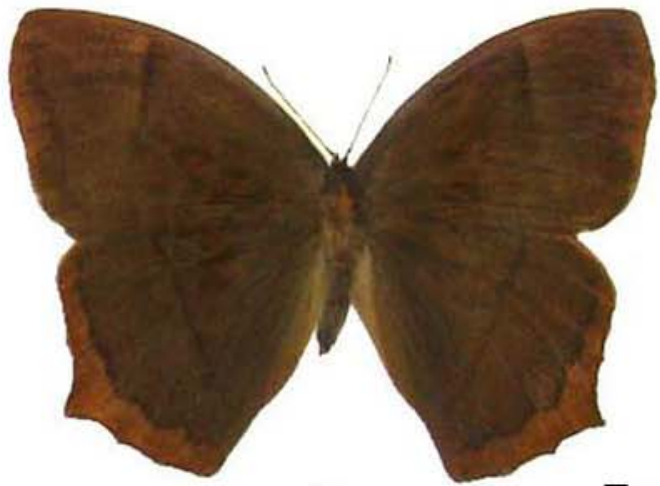

(D)

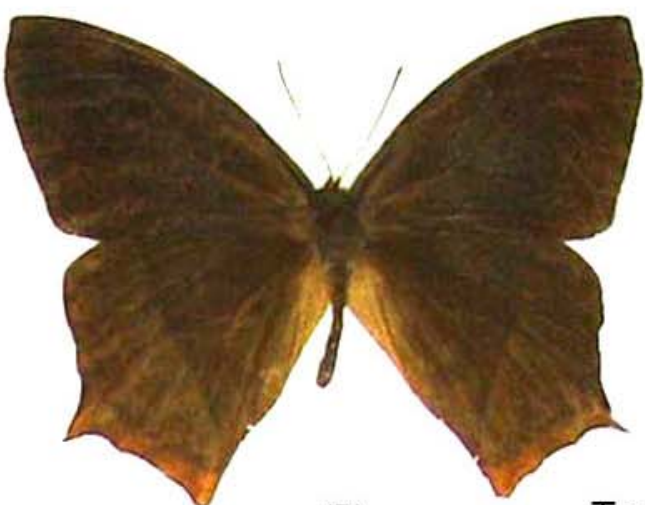

(D)

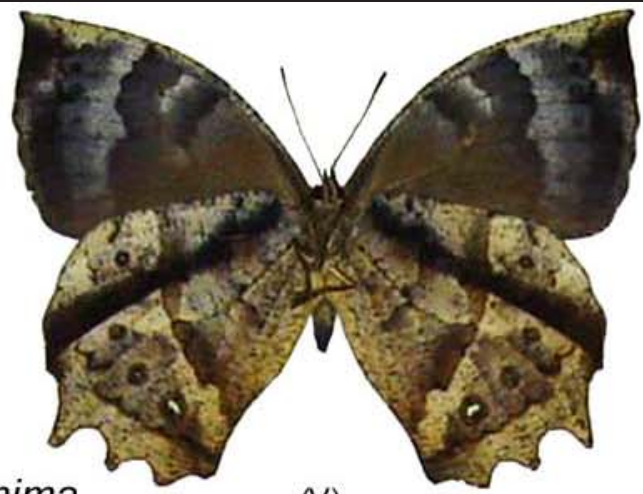

(V)

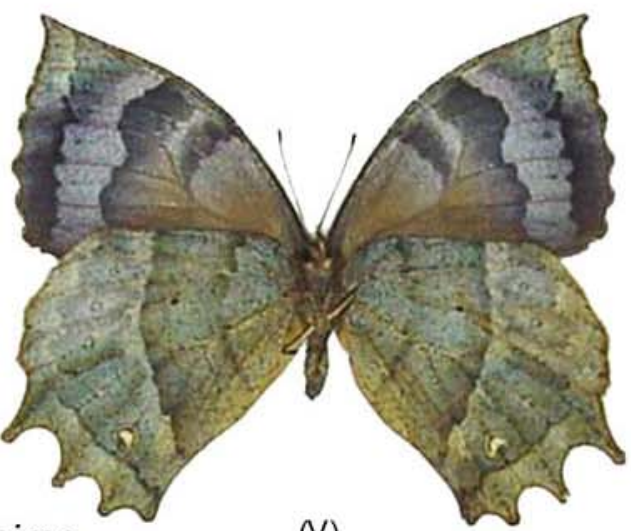

(v)

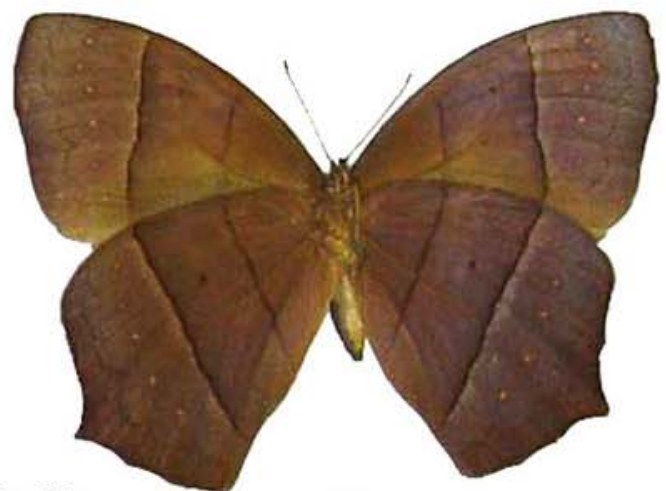

(V)

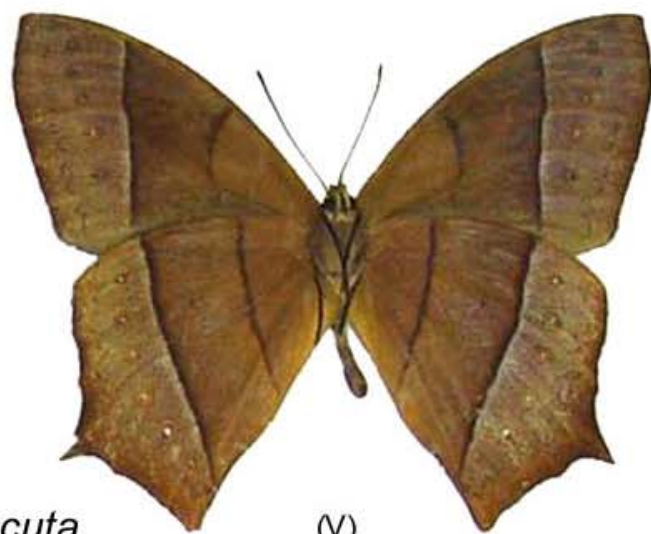

(v) 


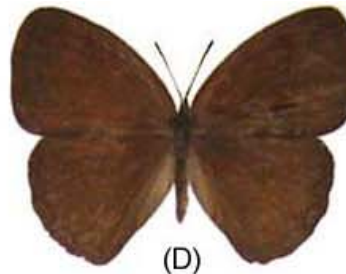

Taydebis peculiaris

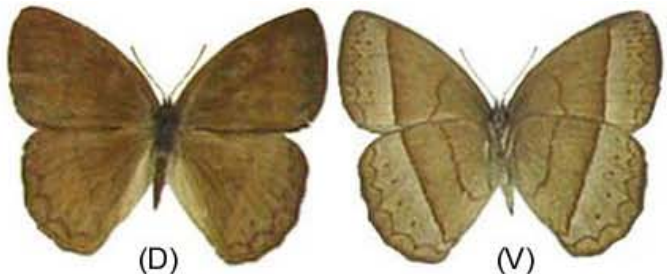

(v)
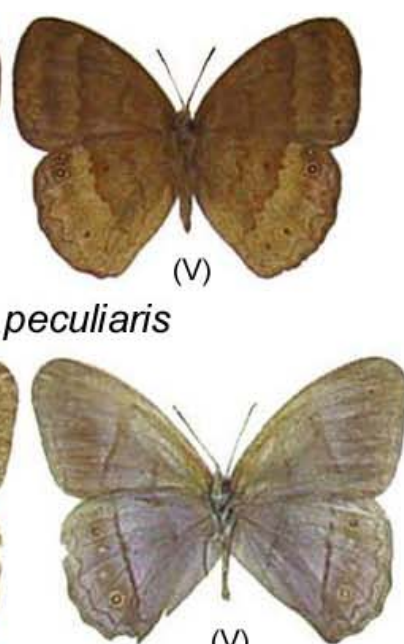

(V)

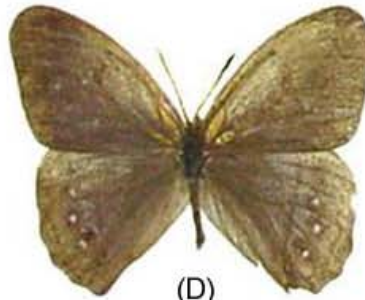

Archeuptychia cluena

Capronnieria abretia

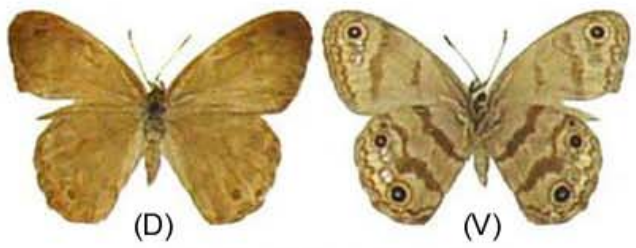

Euptychia ernestina

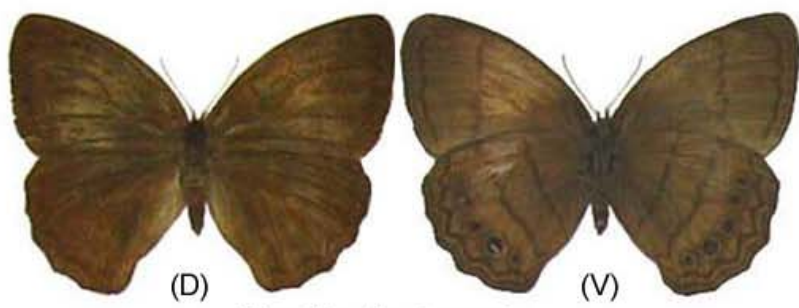

Zischkaia fumata

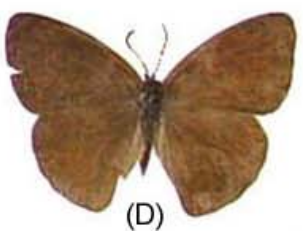

Hermeuptychia hermes

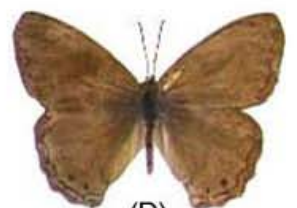

(D)
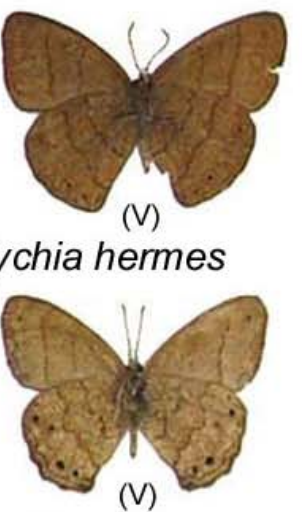

Moneuptychia soter
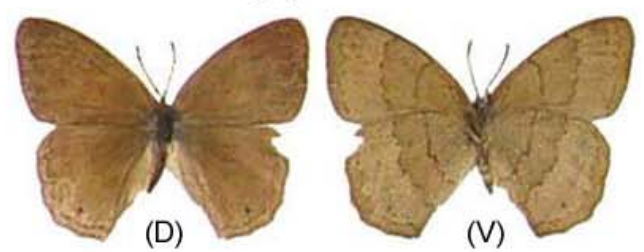

Paryphthimoides phronius

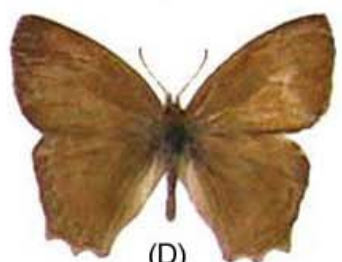

(D)

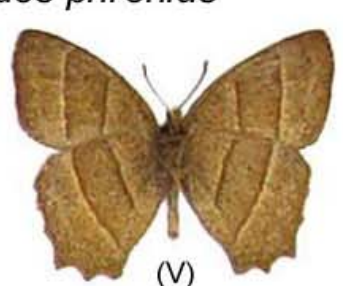

(V)

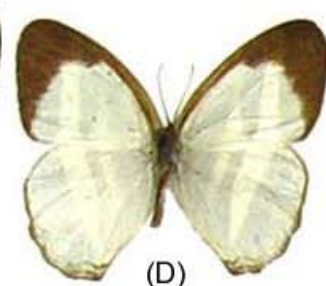

(D)

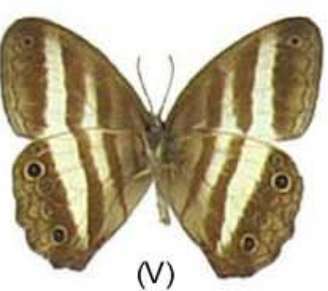

(V)

Pareuptychia interjecta

Yphthimoides angularis

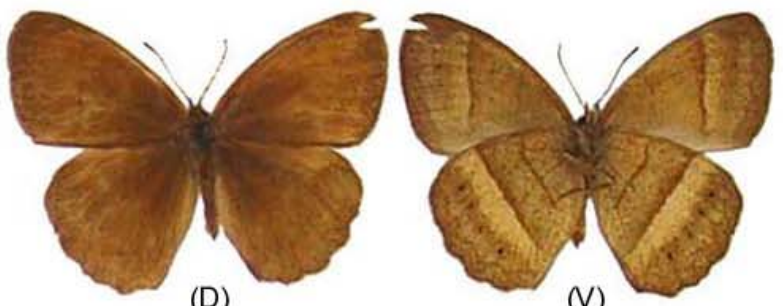

(D)

(v)
Yphthimoides ochracea

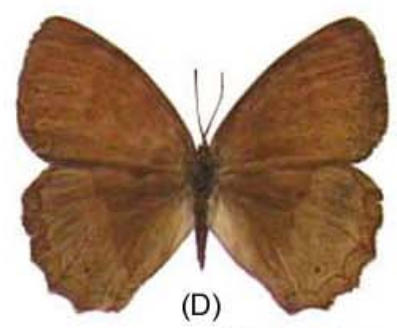

Yphthimoides ochracea 우

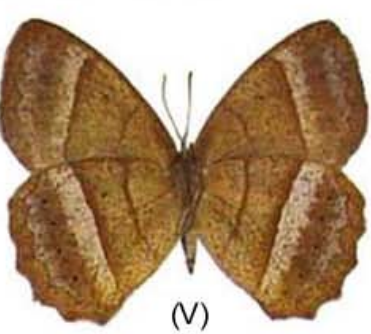

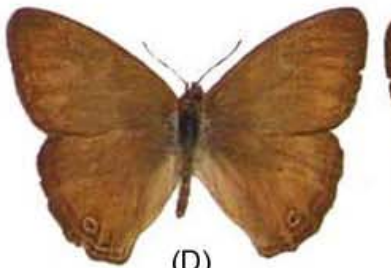

(D)

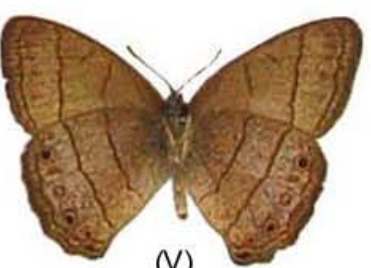

(V)

Yphthimoides disaffecta 


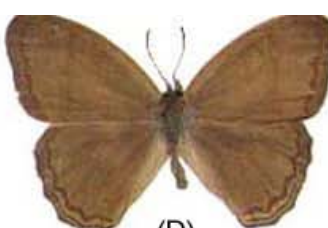

(D)

Yphthimoides grimon

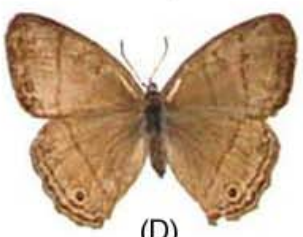

(D)

Yphthimoides castrensis 우

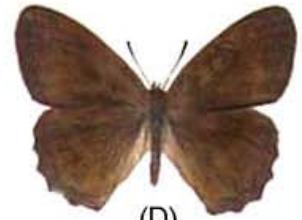

(D)
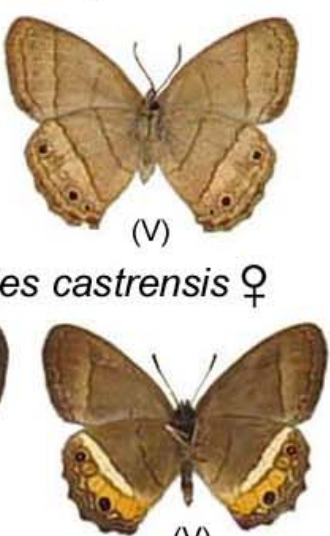

(V)

Splendeuptychia ambra

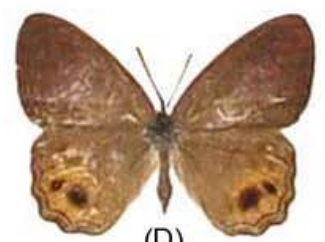

(D)

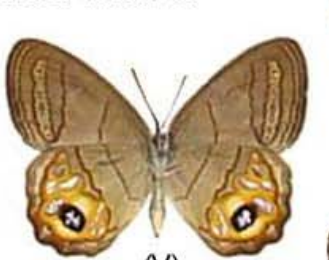

(v)

Splendeuptychia hygina

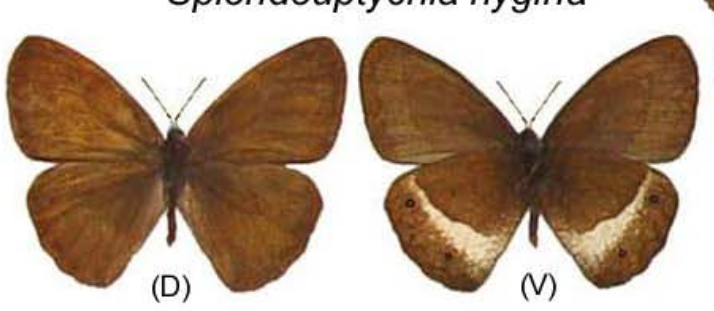

"Euptychia" pronophila

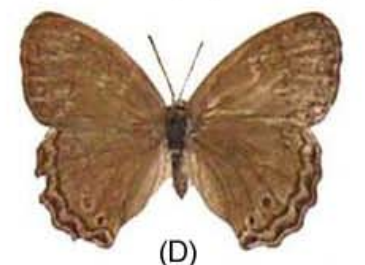

(D)

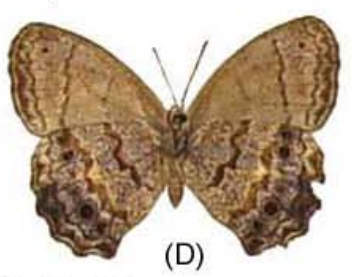

(D)
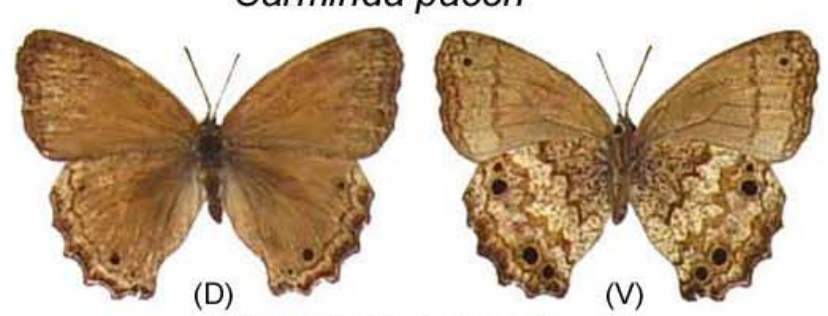

Carminda griseldis

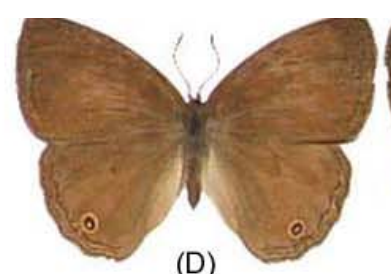

(D)

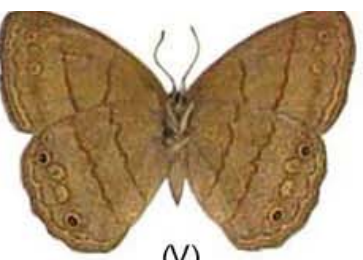

(v)

Yphthimoides affinis
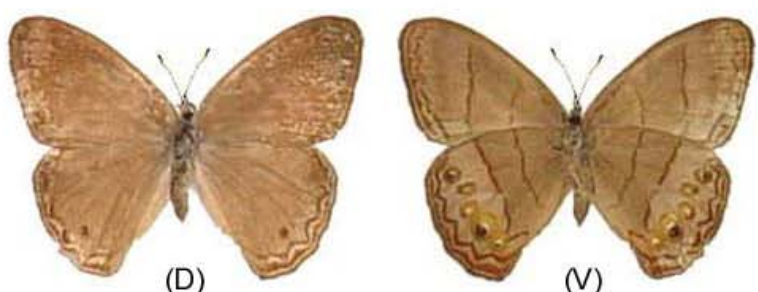

Splendeuptychia doxes

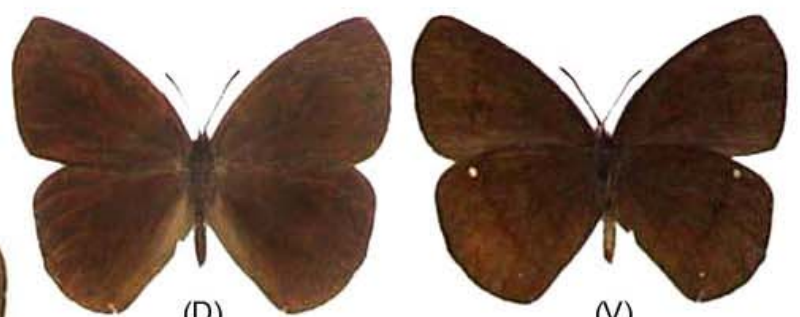

(D)

(v)

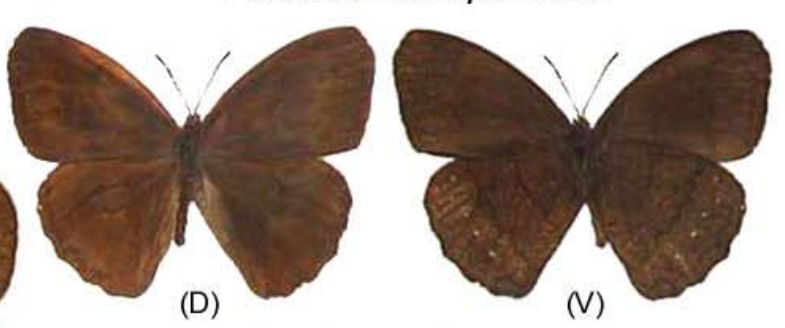

Forsterinaria necys

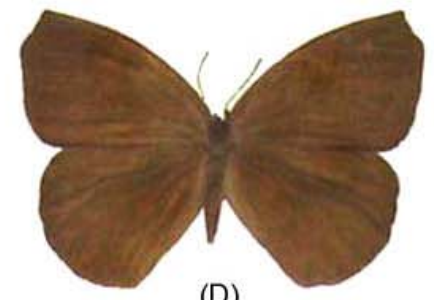

(D)

Godartiana muscosa

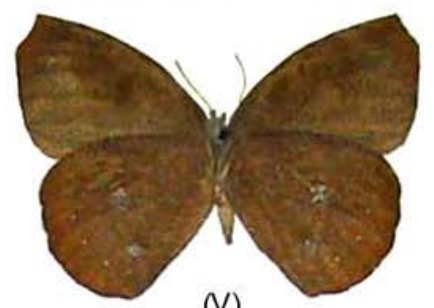

(v)

Prancha 10 - Satyrinae frugívoras da Reserva Estadual do Morro Grande e região de Caucaia do Alto, Cotia/SP, Brasil 


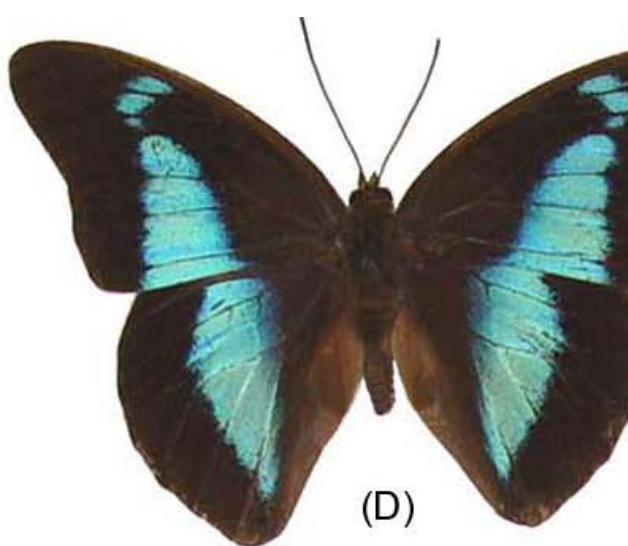

Archaeoprepona chalciope

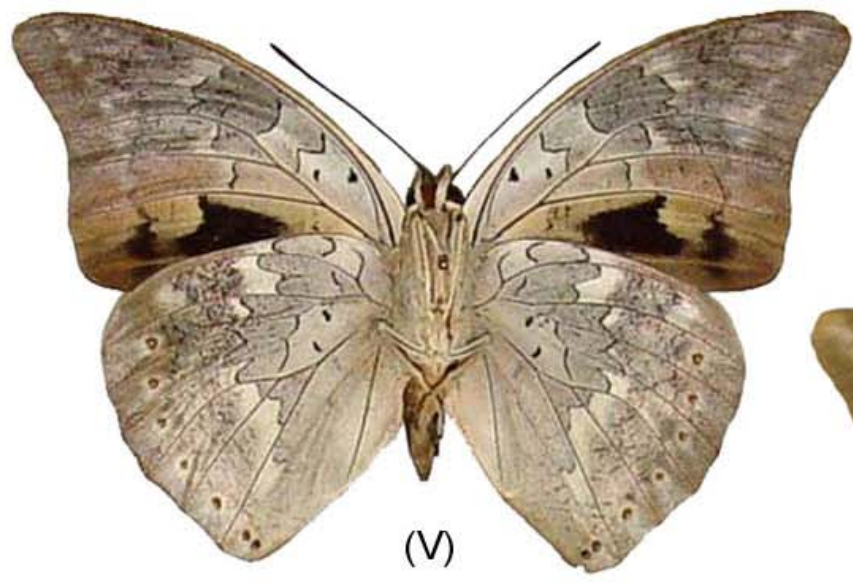

Archaeoprepona demophoon

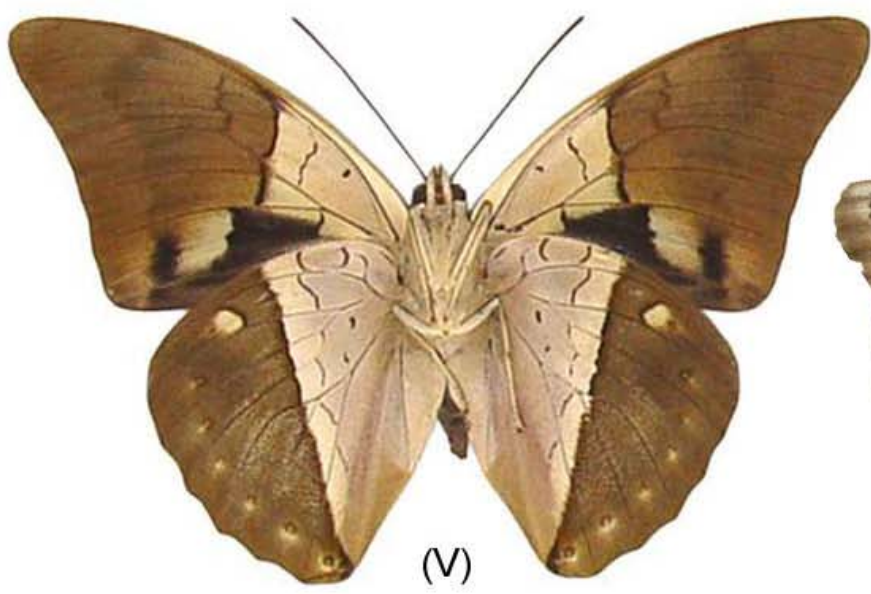

Archaeoprepona amphimachus

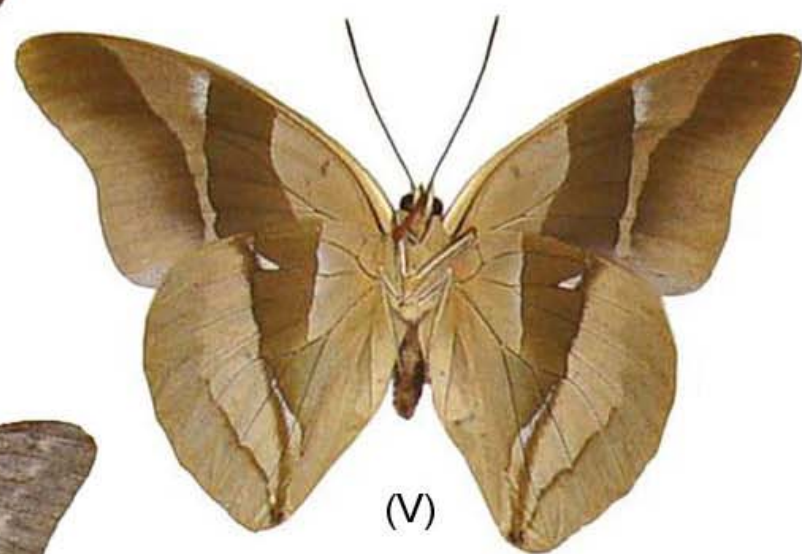

Archaeoprepona chalciope

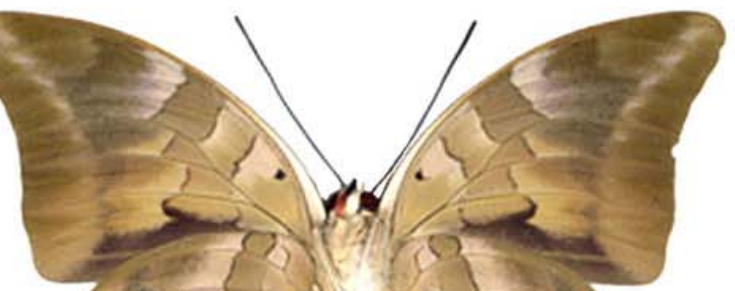

1

(V)

\section{Archaeoprepona demophon}

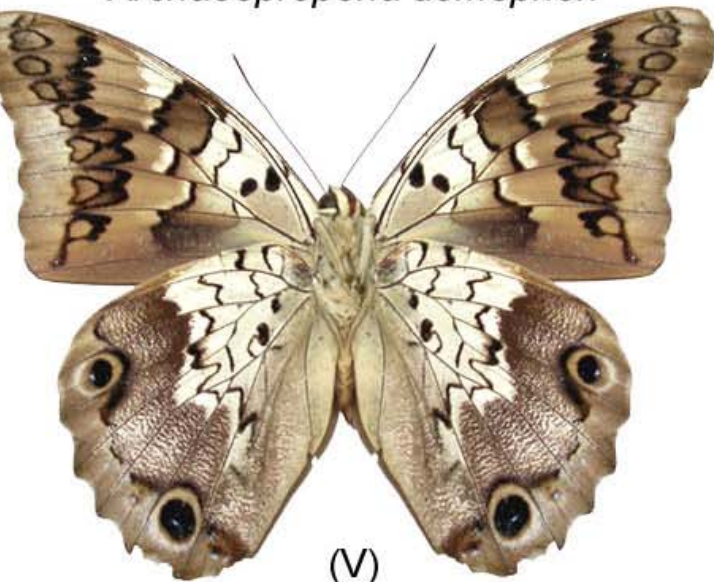

Prepona pylene

Prancha 11 - Charaxinae frugívoras da Reserva Estadual do Morro Grande e região de Caucaia do Alto, Cotia/SP, Brasil 


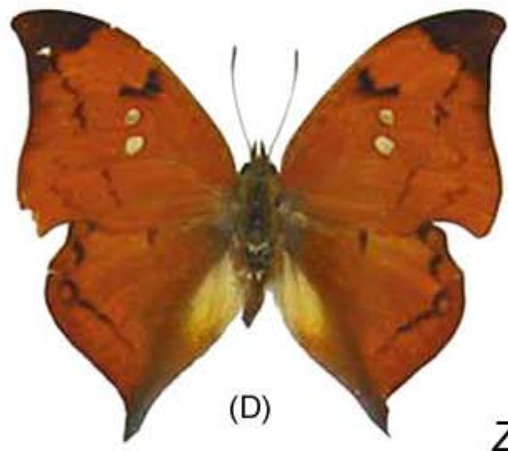

Zaretis itys
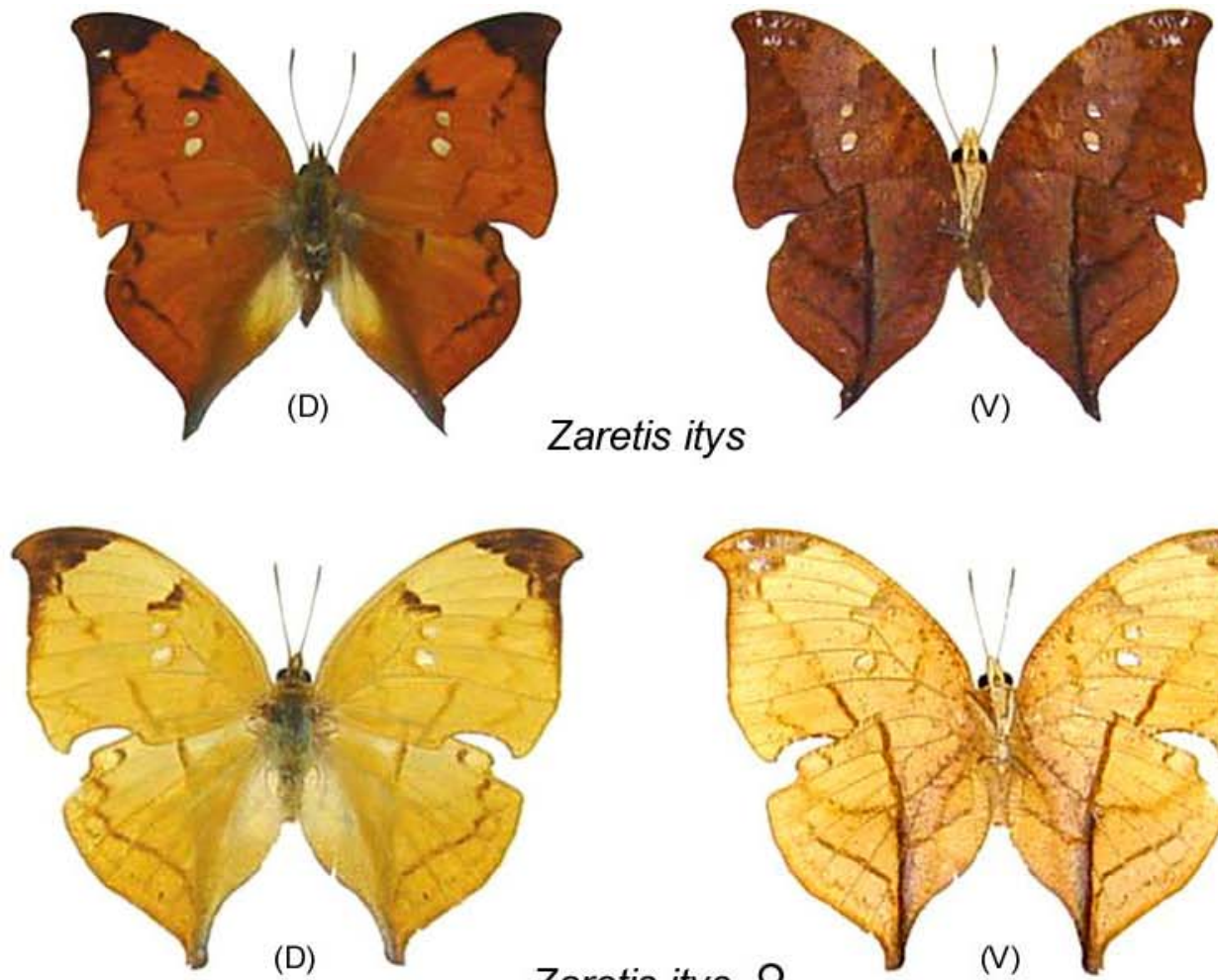

Zaretis itys 우
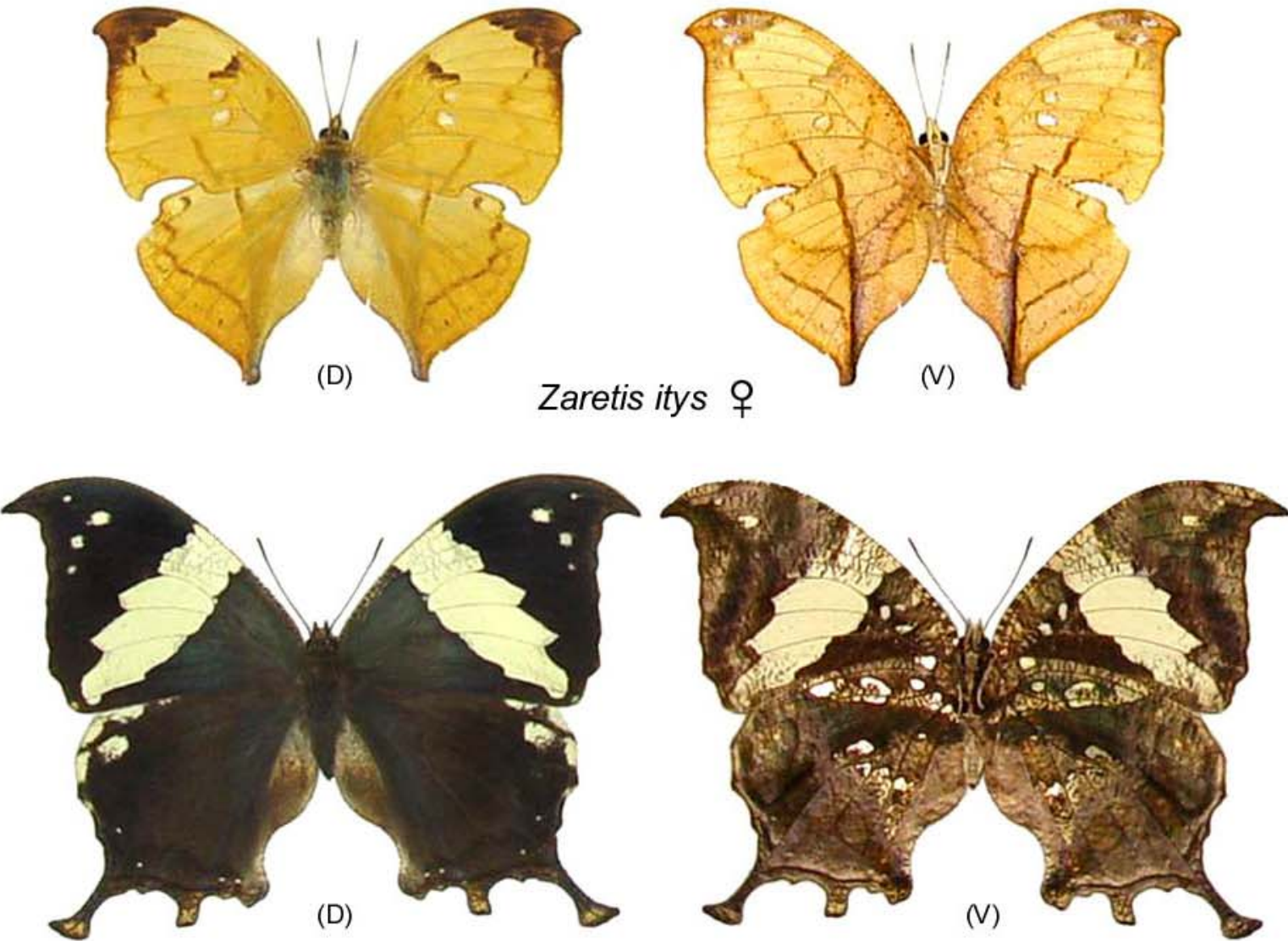

Hypna clytemnestra

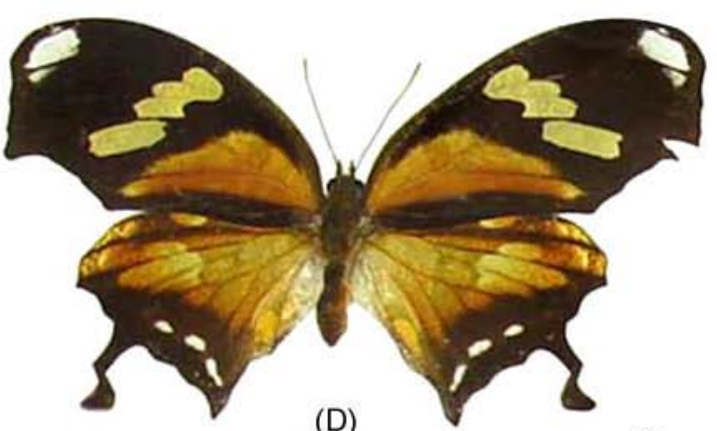

(D)

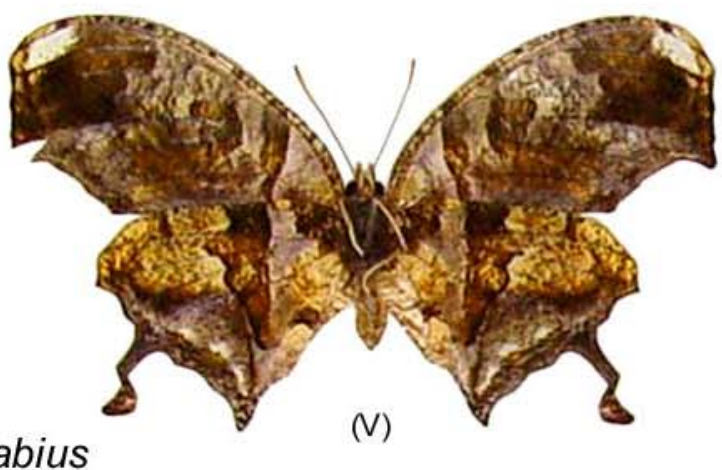

Prancha 12 - Charaxinae frugívoras da Reserva Estadual do Morro Grande e região de Caucaia do Alto, Cotia/SP, Brasil 


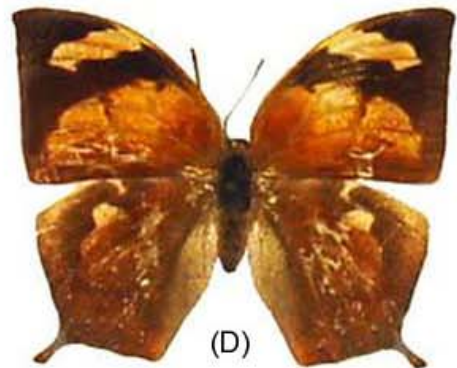

Memphis ryphea 우

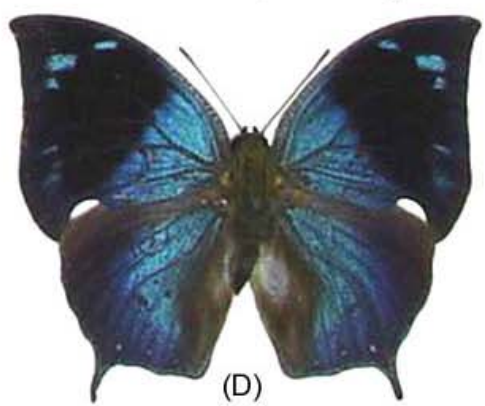

Memphis morvus

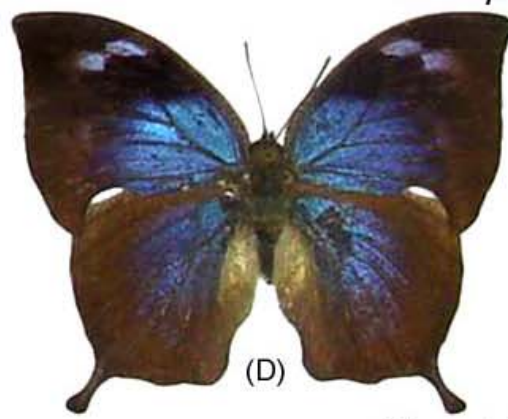

Memphis morvus 우

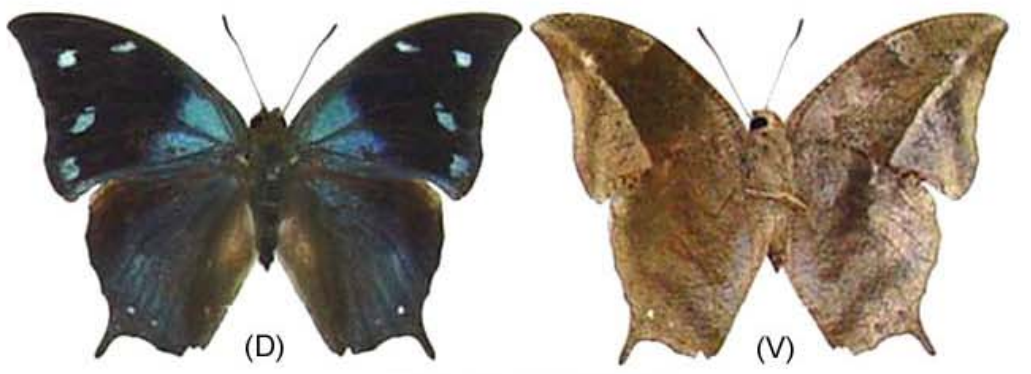

Memphis appias
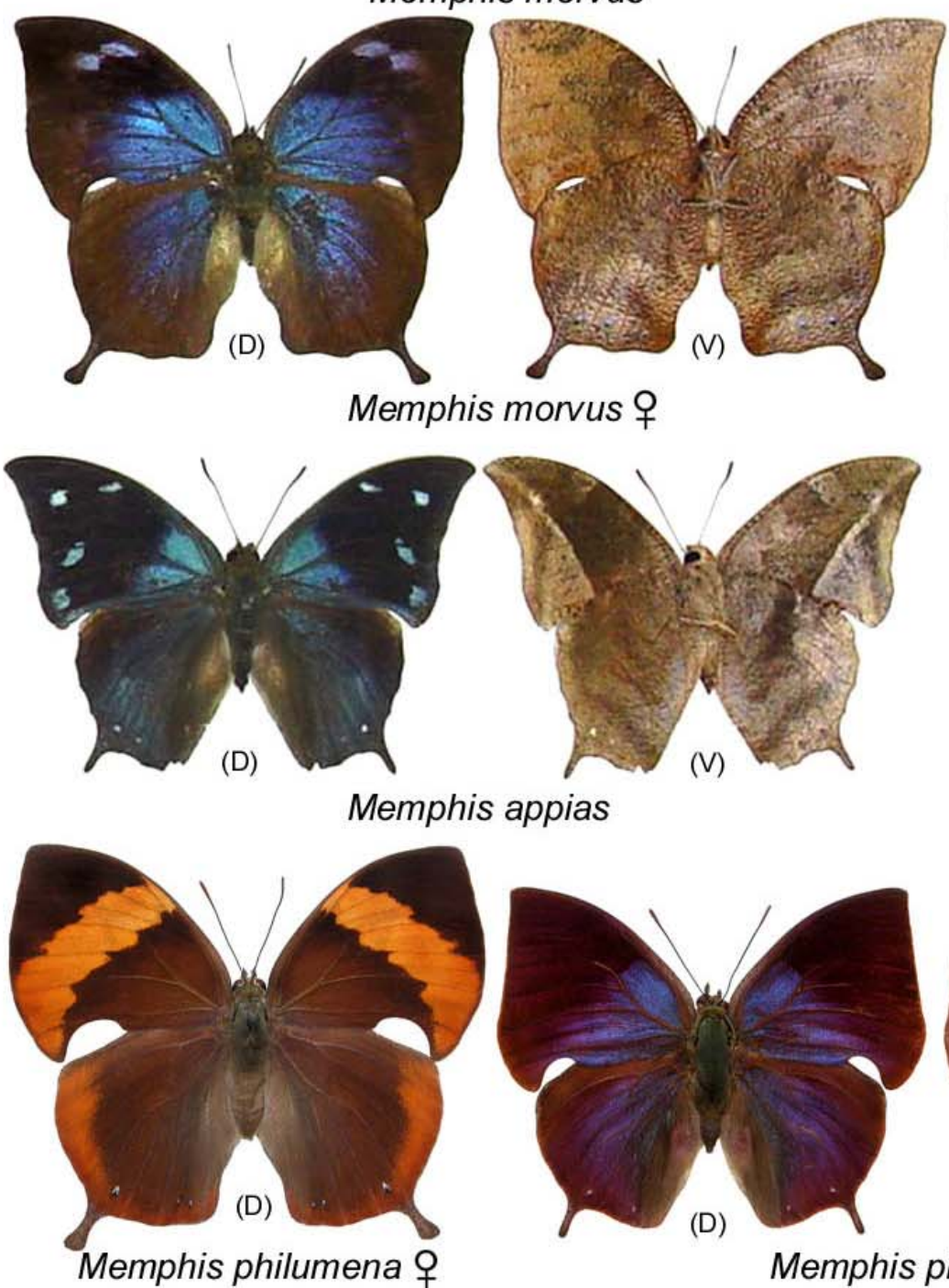

(D)

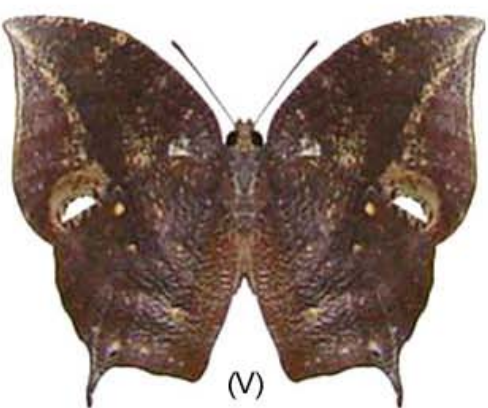

(v)
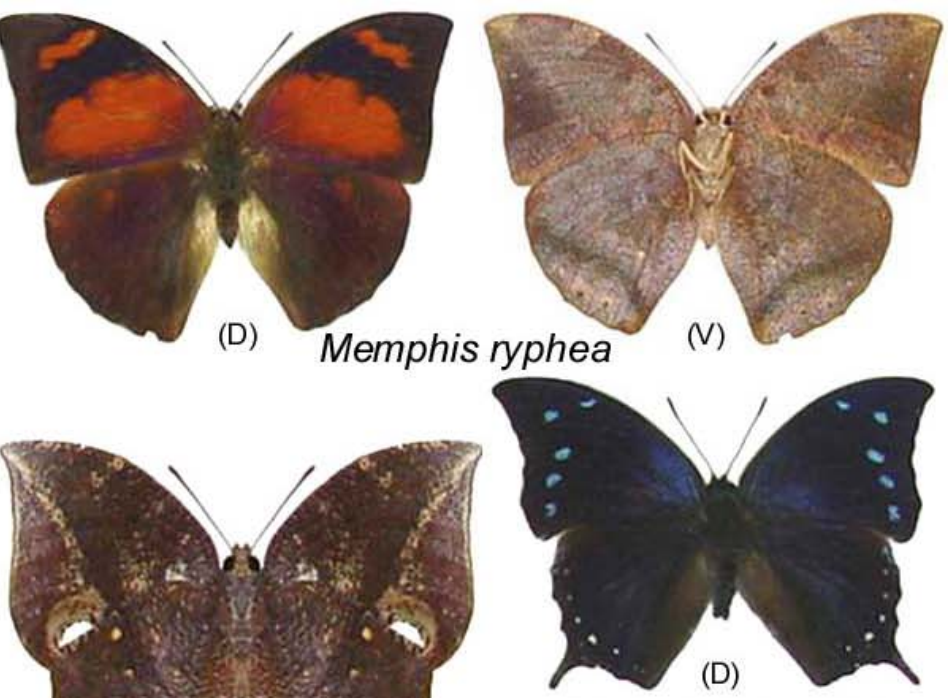

Memphis arginussa

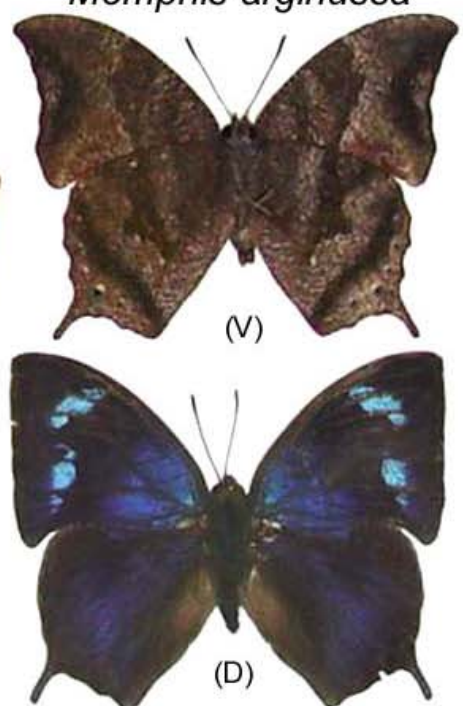

Memphis otrere
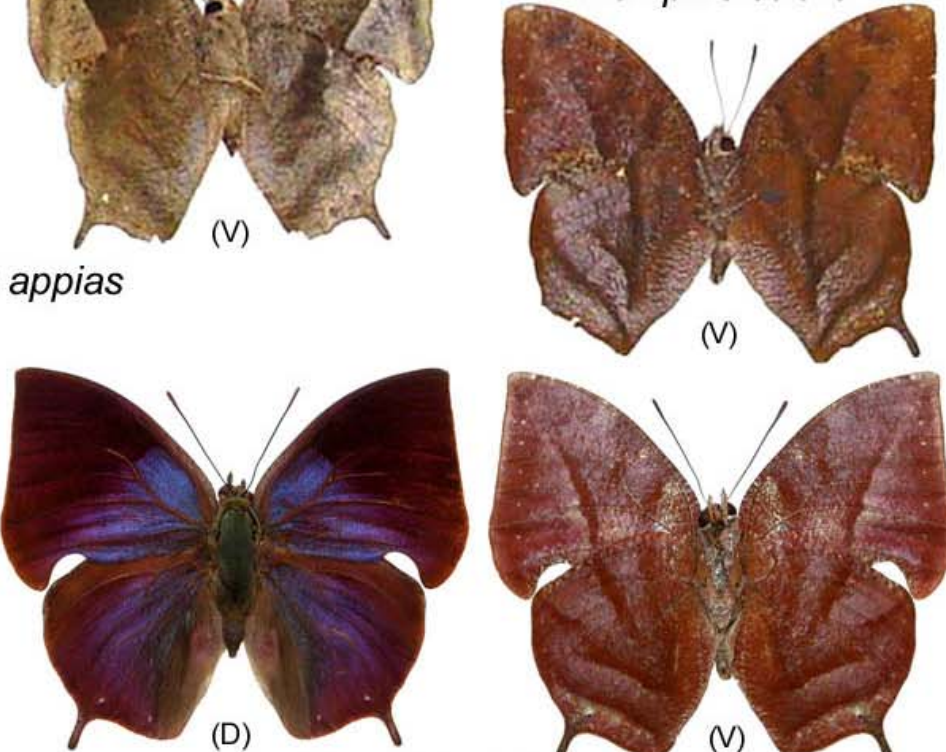

Memphis philumena

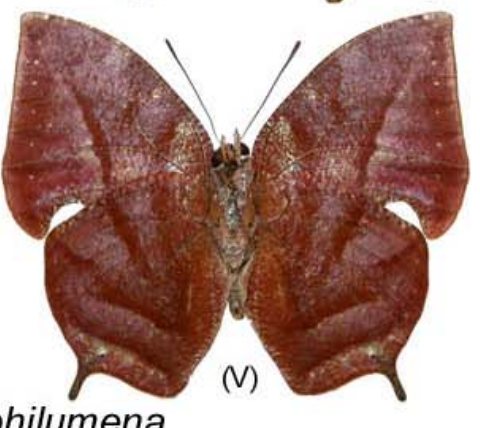

Prancha 13 - Charaxinae frugívoras da Reserva Estadual do Morro Grande e região de Caucaia do Alto, Cotia/SP, Brasil 


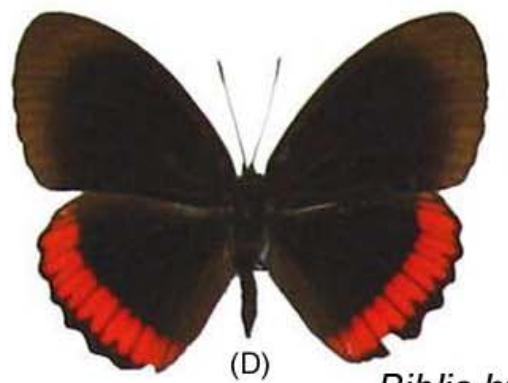

(D)

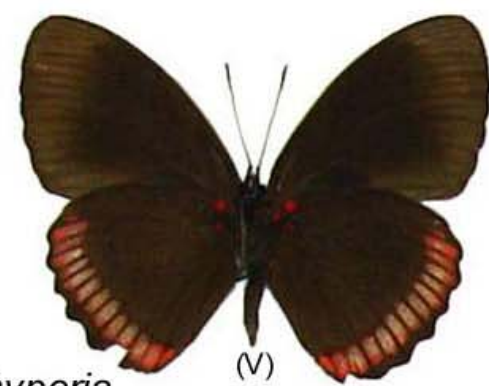

Biblis hyperia

(v)

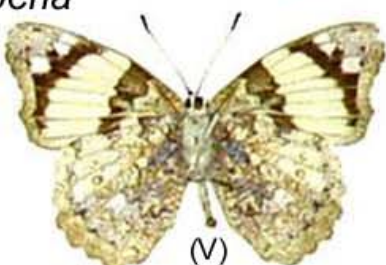

(D)

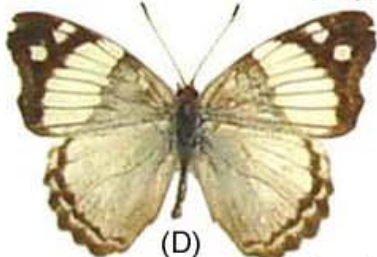

\section{Eunica margarita}
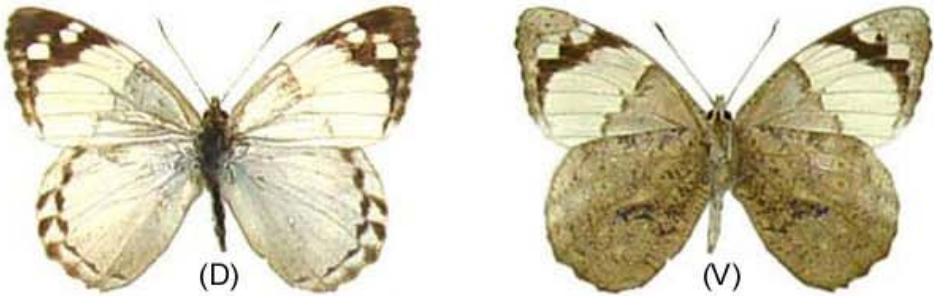

Eunica eburnea

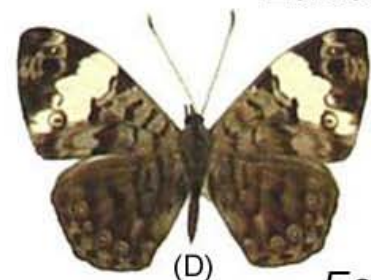

Ectima thecla

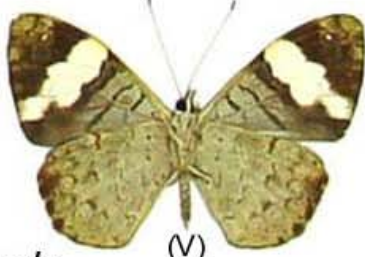

(v)

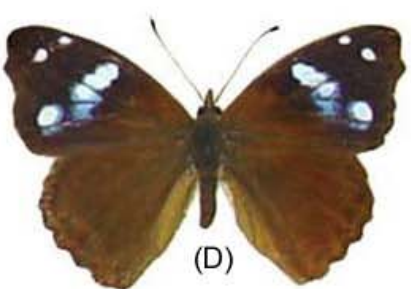

Cybdelis phaesyla

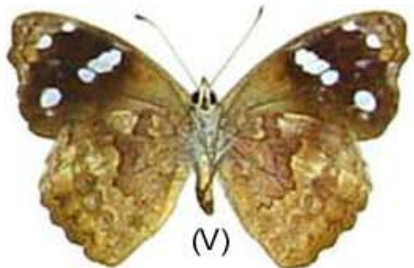

\section{Eunica tatila}

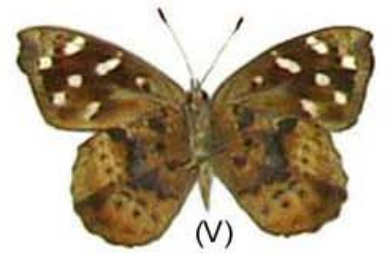

(v)

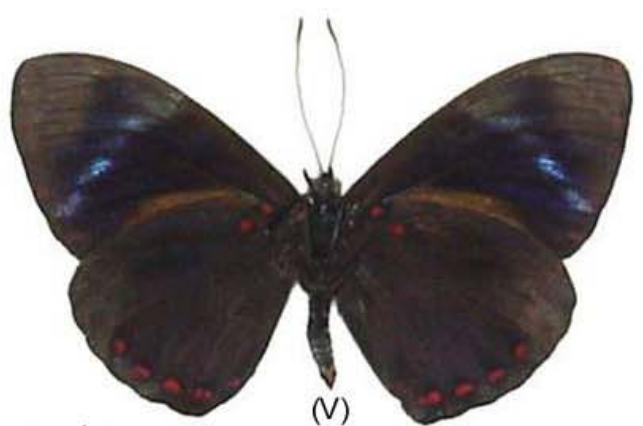

Hamadryas arete

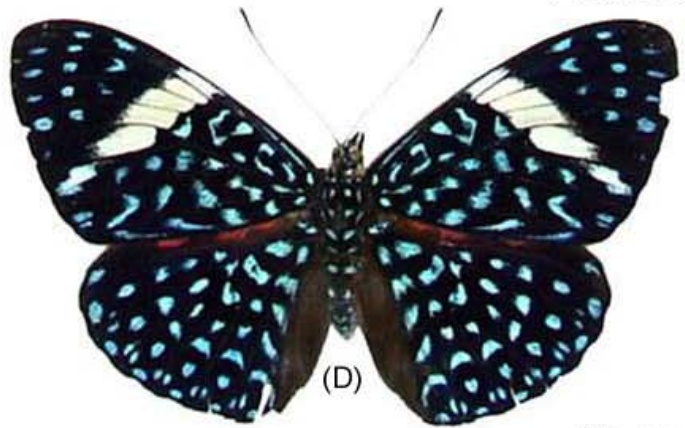

Hamadryas arete $ᄋ$

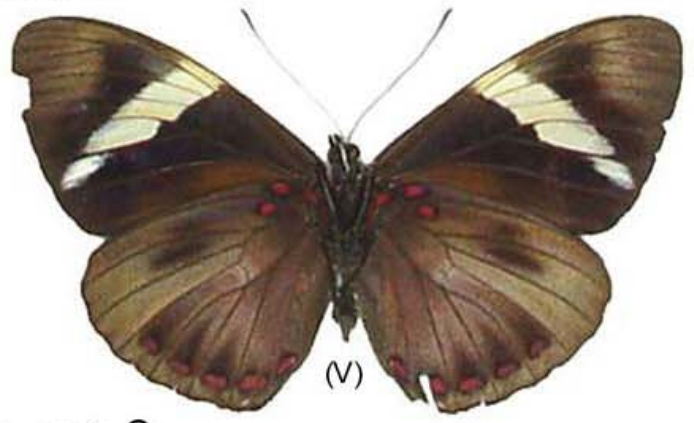

Prancha 14 - Biblidinae frugívoras da Reserva Estadual do Morro Grande e região de Caucaia do Alto, Cotia/SP, Brasil 


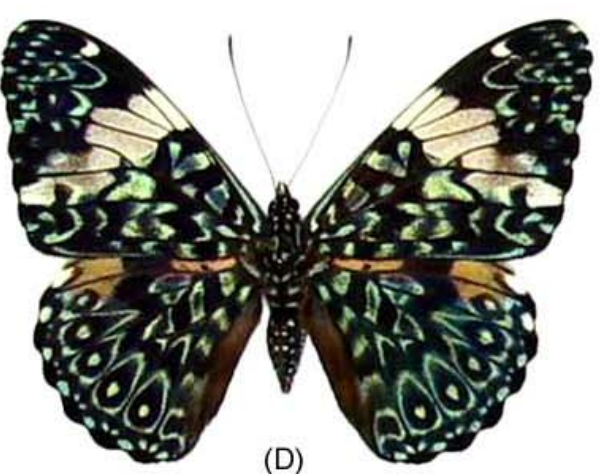

Hamadryas amphinome

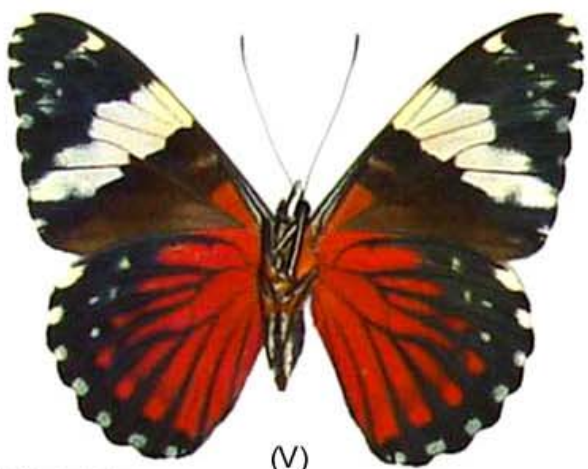

(v)

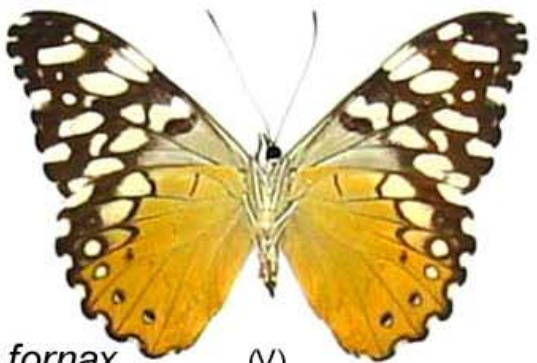

(D)

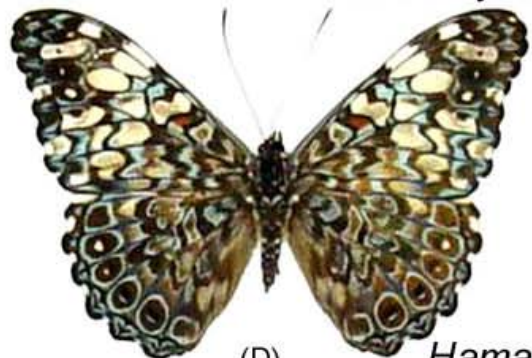

Hamadryas fornax

(v)

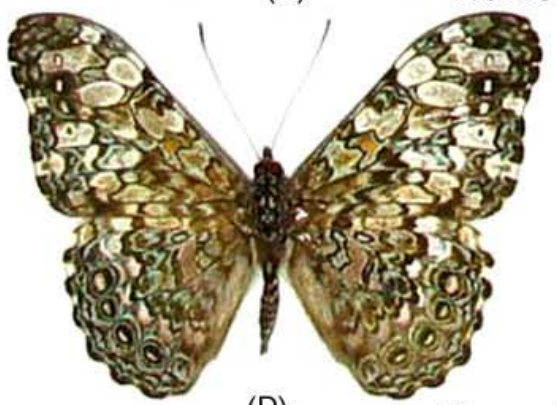

(D)

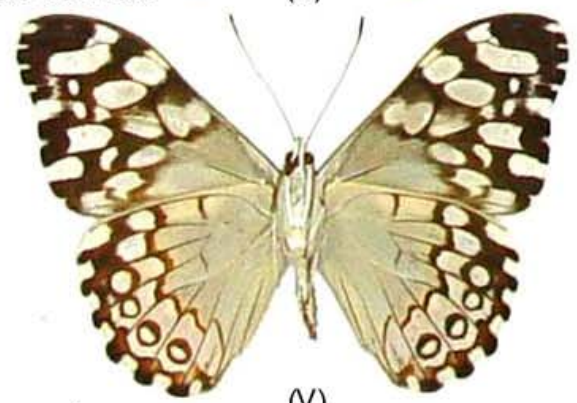

Hamadryas epinome

(v)

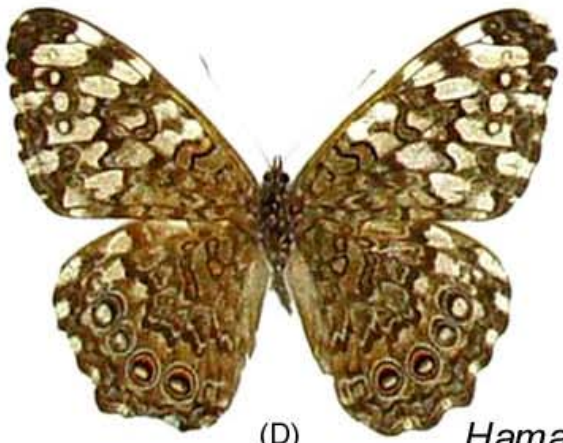

(D)

Hamadryas februa
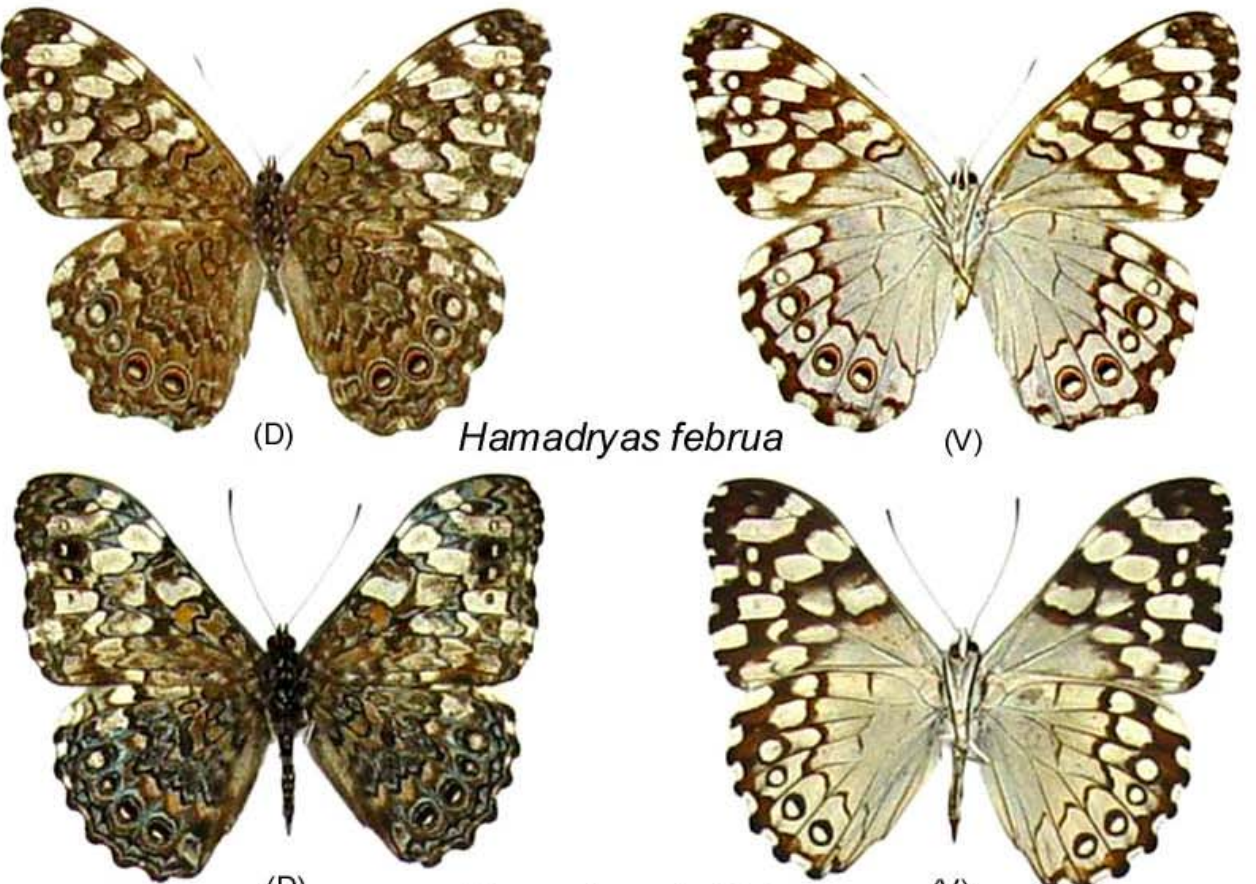

(D)

Hamadryas iphthime

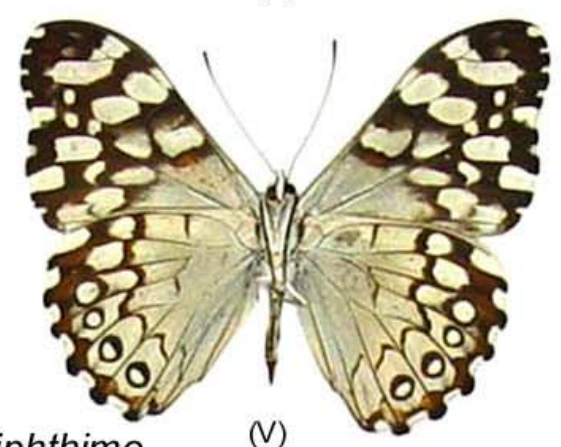

(v)

Prancha 15 - Biblidinae frugivoras da Reserva Estadual do Morro Grande e região de Caucaia do Alto, Cotia/SP, Brasil

http://www.biotaneotropica.org.br 

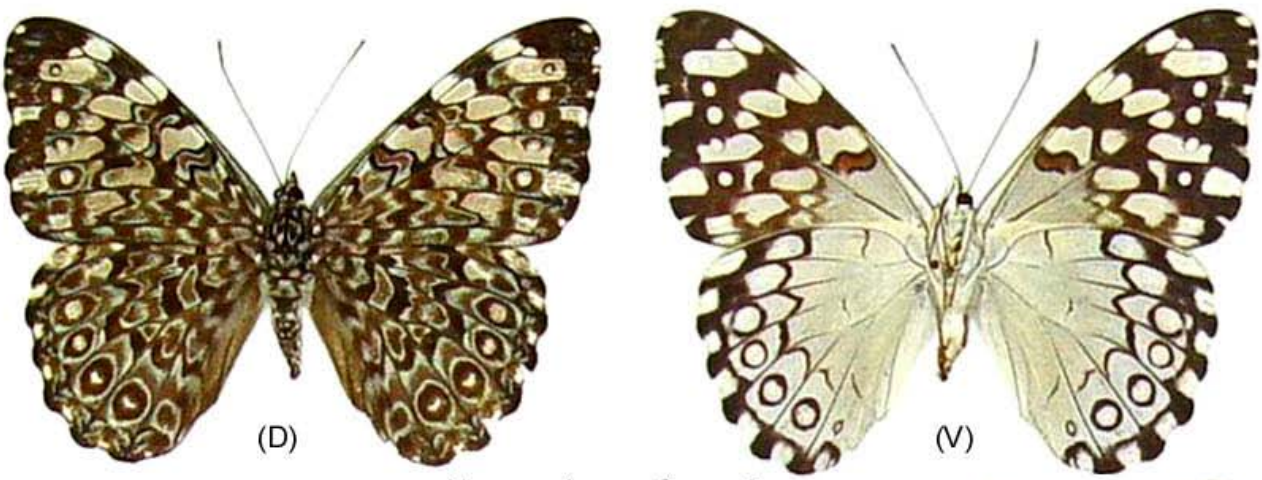

Hamadryas feronia
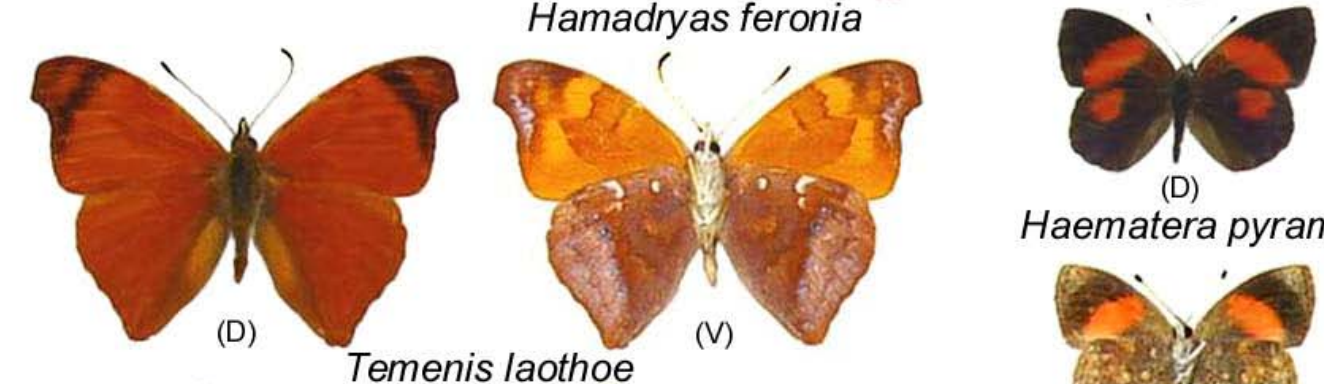

(D)

Haematera pyrame
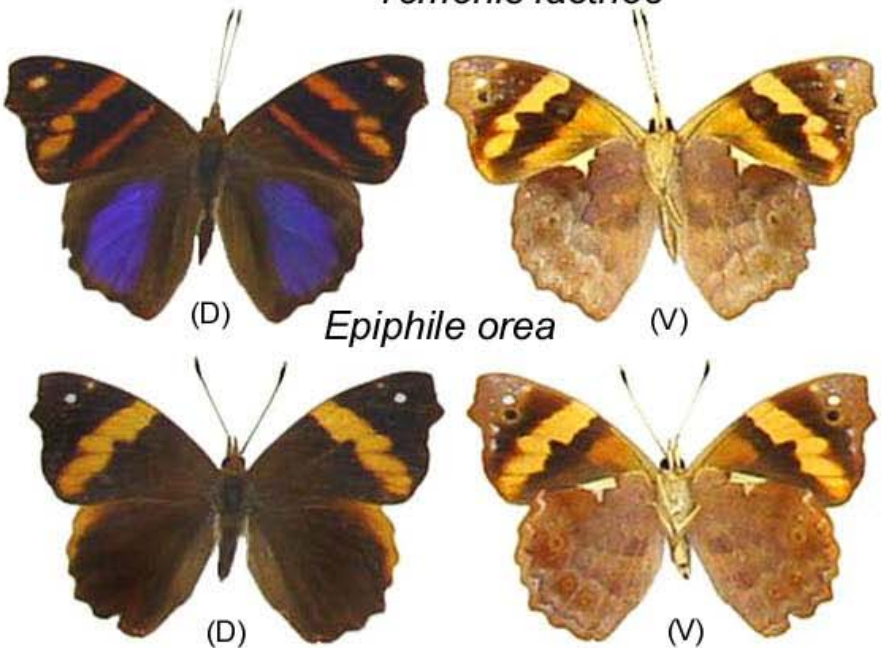

Epiphile orea 우
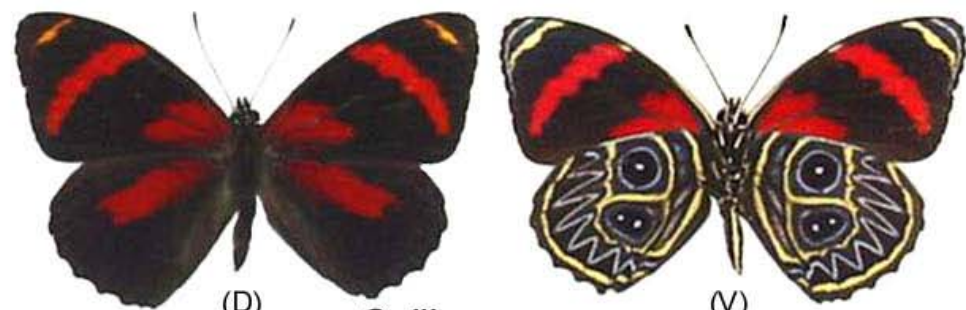

Callicore sorana
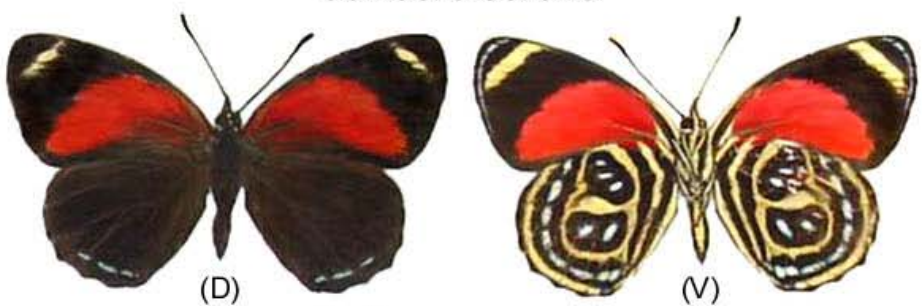

Callicore pygas

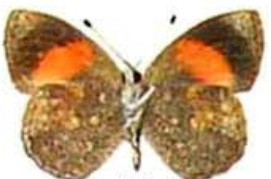

(v)

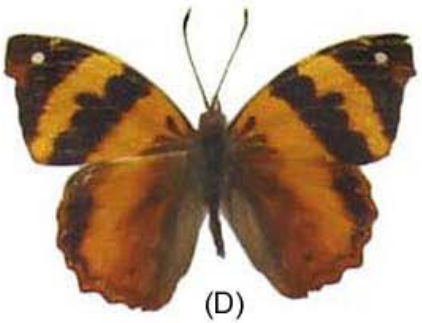

Epiphile huebneri
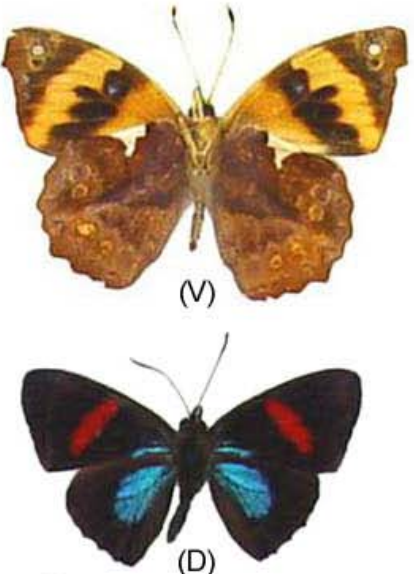

Callicore hydaspes

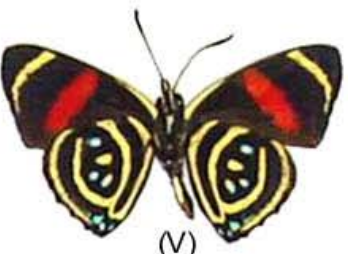

Prancha 16 - Biblidinae frugivoras da Reserva Estadual do Morro Grande e região de Caucaia do Alto, Cotia/SP, Brasil 

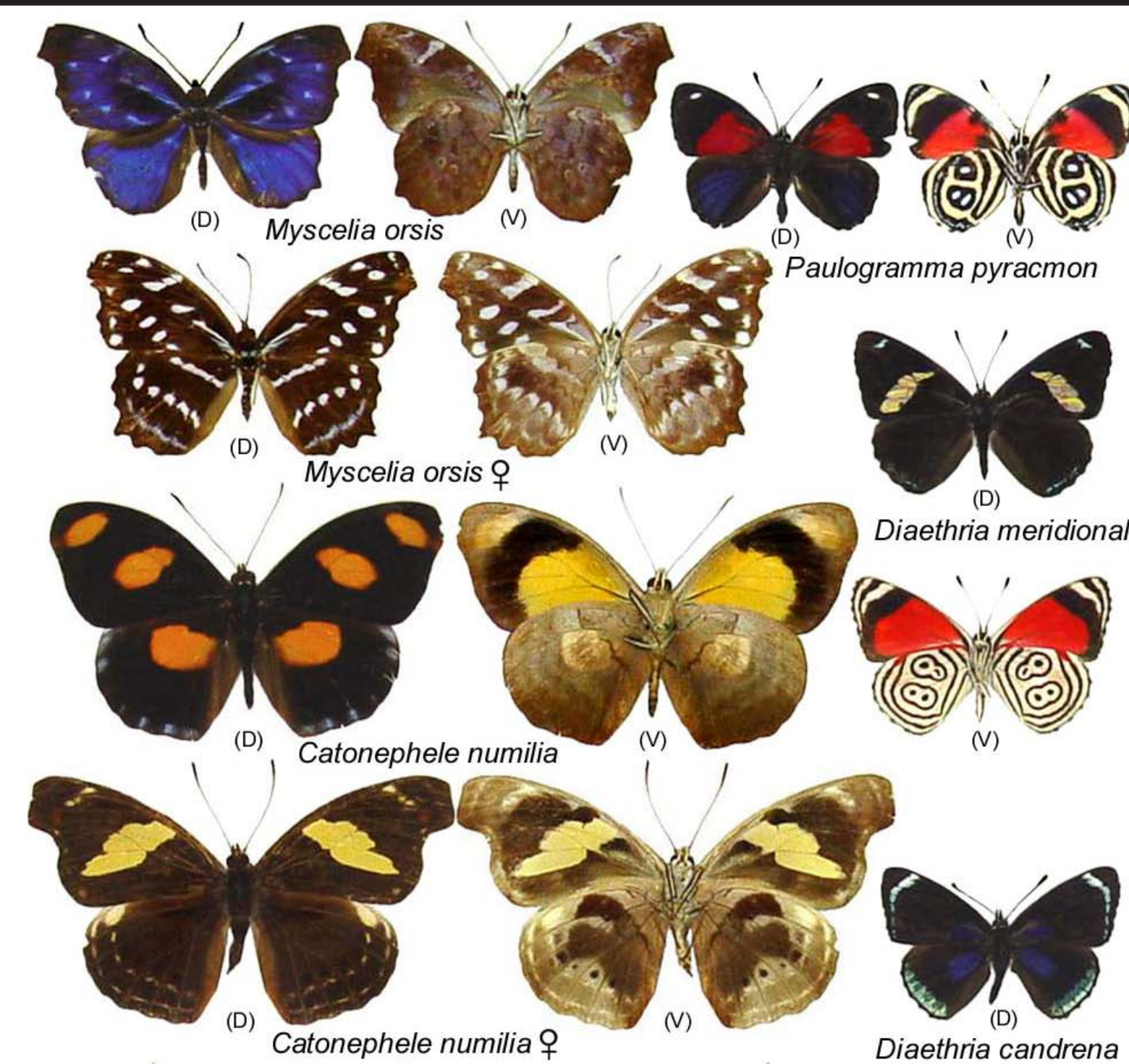

D)

(V)

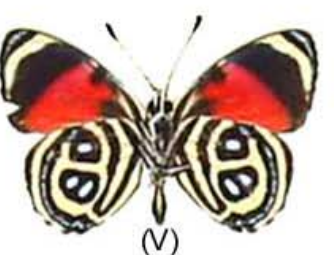

Paulogramma pyracmon

Diaethria meridionalis

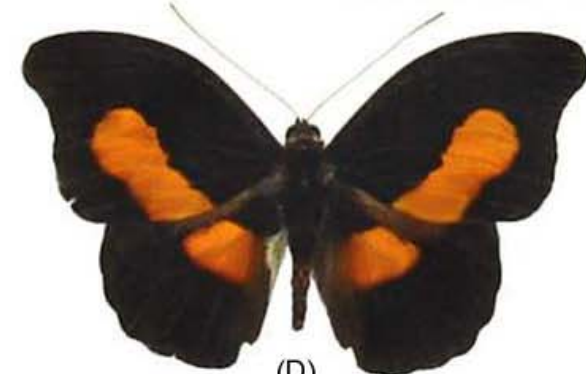

(D) Catonephele acontius
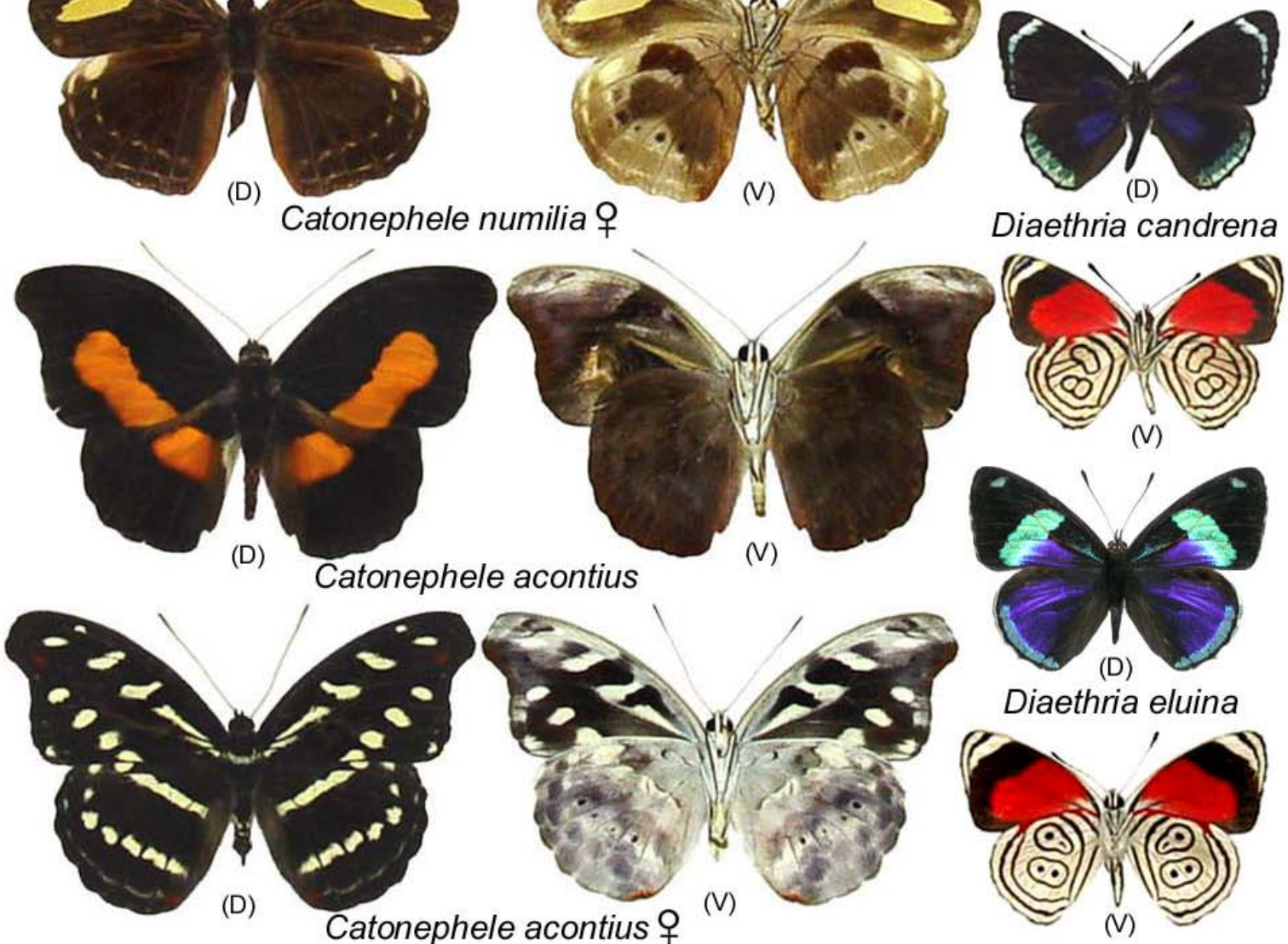

Diaethria candrena

Prancha 17 - Biblidinae frugívoras da Reserva Estadual do Morro Grande e região de Caucaia do Alto, Cotia/SP, Brasil 


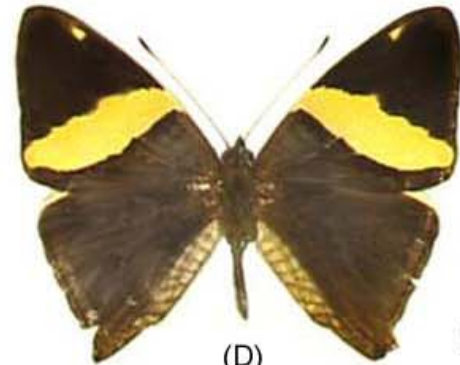

(D)
Colobura dirce

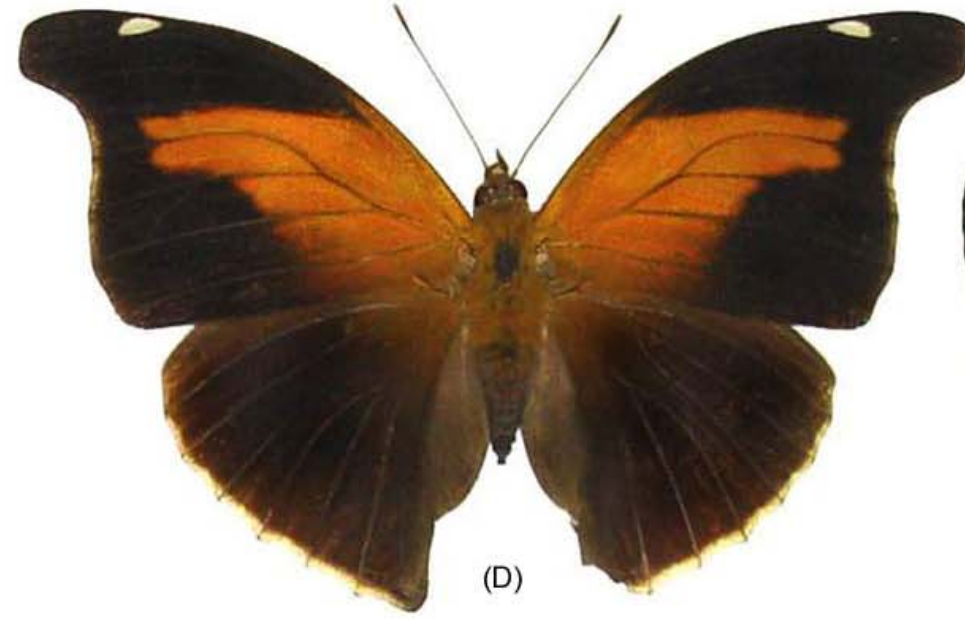

(D)

Historis odius
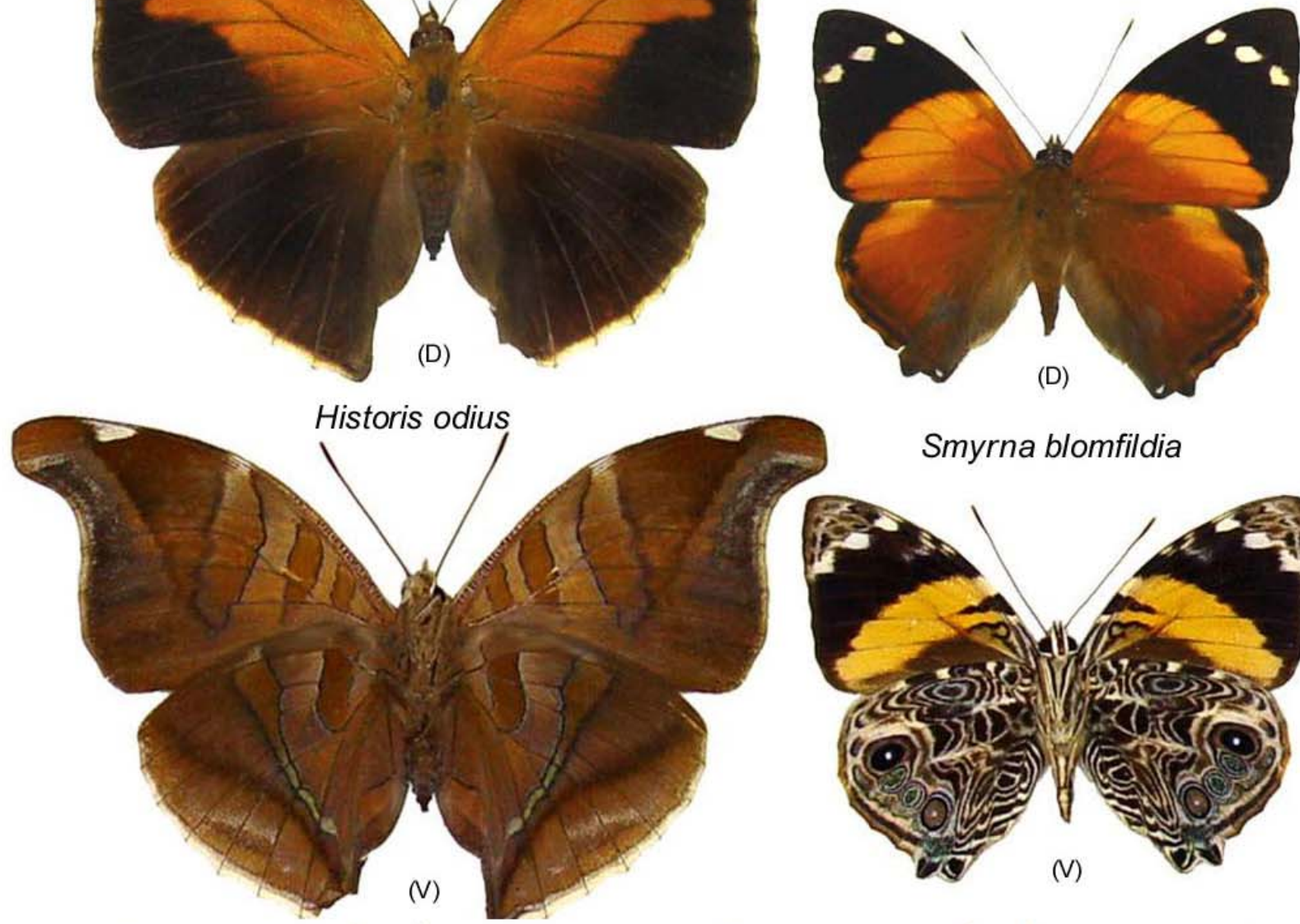

(D)

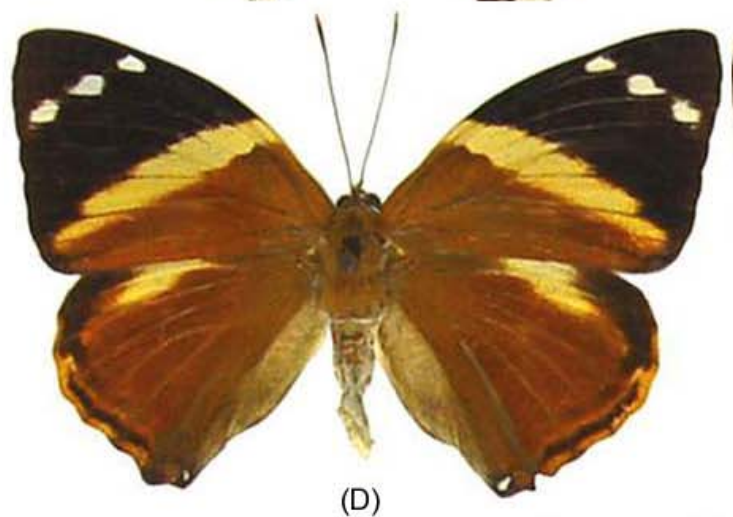

Smyrna blomfildia우

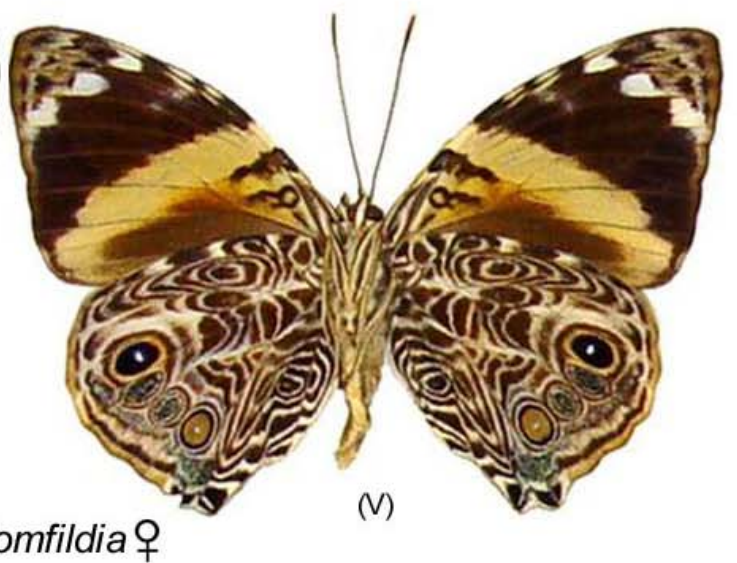

Prancha 18 - Coloburini (Nymphalinae) frugívoras da Reserva Estadual do Morro Grande e região de Caucaia do Alto, Cotia/SP, Brasil 


\section{Apêndice 1}

Lista das espécies de borboletas frugívoras (Nymphalidae) encontradas na Reserva do Morro Grande e em Caucaia do Alto. ADG = Amplitude de distribuição geográfica

\section{Brassolinae}

Narope cyllarus Westwood, 1850

Dasyophthalma creusa (Hübner, 1812)

Dasyophthalma rusina (Godart, 1824)

Opoptera syme (Hübner, 1822)

Opoptera aorsa (Godart, 1824)

Opoptera fruhstorferi (Röber, 1896)

Blepolenis batea (Hübner, 1822)

Opsiphanes invirae (Hüner, 1818)

Opsiphanes quiteria (Stoll, 1782)

Opsiphanes cassiae (Linnaeus, 1758)

Catoblepia amphirhoe (Hübner, 1822)

Eryphanis reevesi Doubleday, 1849

Caligo arisbe Hübner, 1820

Caligo illioneus (Cramer, 1776)

Caligo beltrao (Illiger, 1801)

Caligo brasiliensis (Felder, 1862)

\section{Morphinae}

Morpho catenarius Perry, 1811

Morpho achilles (Linnaeus, 1758)

\section{Biblidinae}

Biblis hyperia (Cramer, 1780)

Cybdelis phaesyla Hübner, 1827

Ectima thecla (Fabricius, 1796)

Hamadryas arete (Doubleday, 1847)

Hamadryas amphinome (Linnaeus, 1767)

Hamadryas epinome (Felder \& Felder, 1867)

Hamadryas februa (Hübner, 1823)

Hamadryas feronia (Linnaeus, 1758)

Hamadryas iphthime (Bates, 1864)

Hamadryas fornax (Hübner, 1823)

Myscelia orsis (Drury, 1782)

Catonephele numilia (Hewitson, 1852)

Catonephele acontius (Linnaeus, 1771)

Eunica margarita (Godart, 1824)

Eunica eburnea Frühstorfer, 1907

Eunica tatila (Rerrich-Schäffer, 1855)

Temenis laothoe (Cramer, 1777)

Epiphile huebneri Hewitson, 1867

Epiphile orea Hübner, 1823

Diaethria candrena (Godart, 1821)

Diaethria meridionalis Bates, 1864

Diaethria eluina (Hewitson, 1852)

Haematera pyrame (Hübner, 1819)

Paulogramma pyracmon (Godart, 1823)

Callicore hydaspes (Drury, 1782)

Callicore pygas (Godart, 1823)

Callicore sorana (Godart, 1823)

ADG
III
III
III
III
VI
II-s
VI
VII
VII
V
IV
IV
II-s
VI
III
VI

IV

VII

VII

VI

VII

IV

VII

V

VII

VII

VII

VII

IV

VII

VI

IV

IV

VII

VII

IV

VI

V

VII

II-i

VII

V

IV

V

\section{Charaxinae}

Archaeoprepona demophon (Linnaeus, 1758)

Archaeoprepona demophoon (Hübner, 1819)

Archaeoprepona amphimachus (Fabricius, 1775) VII

Archaeoprepona chalciope (Hübner, 1825) VI

Prepona pylene (Frühstorfer, 1915) III

Consul fabius(Butler, 1873) VII

Zaretis itys (Cramer, 1777) VII

Hypna clytemnestra (Cramer, 1777) VII

Memphis ryphea (Geyer, 1834)

Memphis arginussa (Geyer, 1832)

VII

VII

Memphis appias (Hübner, 1825)

Memphis otrere (Hübner, 1825)

Memphis morvus (Fabricius, 1775)

Memphis philumena (Doubleday, 1850)

VII

VI

Nymphalinae (Coloburini)

Colobura dirce (Linnaeus, 1758)

Historis odius (Fabricius, 1775)

VII

Smyrna blomfildia (Fabricius, 1781)

VII

VII

\section{Satyrinae}

Pierella nereis (Drury, 1782)

Eteona tisiphone (Boisduval, 1836)

III

Taygetis laches (Fabricius, 1793)

Taygetis virgilia (Cramer, 1776)

Taygetis acuta Weymer, 1910

Taygetis ypthima Hübner, 1821

Taydebis peculiaris (Butler, 1874)

Capronnieria abretia (Capronnier, 1874)

Euptychia ernestina Weymer, 1910

Carminda paeon (Godart, 1823)

Carminda griseldis (Weymer, 1910)

Pareuptychia interjecta (D' Almeida, 1952)

Archeuptychia cluena (Drury, 1782)

Hermeuptychia hermes (Fabricius, 1775)

Moneuptychia soter (Butler, 1877)

Paryphthimoides phronius (Godart, 1823)

Yphthimoides grimon (Godart, 1824)

Yphthimoides ochracea (Butler, 1867)

Yphthimoides angularis (Butler, 1867)

III

VII

VI

II-s

III

II-s

V

I

III

III

VII

II-n

VII

III

V

IV

IV

IV

Yphthimoides disaffecta (Butler \& Druce, 1874) II-I

Yphthimoides affinis (Butler, 1867) II-I

Yphthimoides castrensis (Schaus, 1902)

Splendeuptychia ambra (Weymer, 1911)

Splendeuptychia doxes (Godart, 1823)

Splendeuptychia hygina (Butler, 1877)

IV

I

IV

IV

Godartiana muscosa (Butler, 1870) III

Zischkaia fumata (Butler, 1867) IV

"Euptychia" pronophila Butler, 1867

Forsterinaria quantius (Godart, 1823) III

Forsterinaria necys (Godart, 1823) 
I - Restrita: ocorrência em poucos pontos esparsos da Mata Atlântica;

II - Partes da Mata Atlântica: distribuição restrita, na mata Atlântica do estado de São Paulo e imediações; II-s = de São Paulo até o Sul do Brasil, II-n = de São Paulo até o Nordeste do Brasil, II-i = apenas interior de São Paulo;

III - Mata Atlântica sensu strictu: litoral, encosta e virada das serras litorâneas

IV - Mata Atlântica sensu latu: igual a 3, incluindo matas semidecíduas e decíduas do interior

V - Extra-Amazônica: cis-andina, exceto Amazônia

VI - Cis-Andina: Neotropical, exceto a região dos Andes

VII - Neotropical: México a Argentina 